\title{
Effect of in situ exopolysaccharide production on physicochemical, rheological, sensory, and microstructural properties of the yogurt drink ayran: An optimization study based on fermentation kinetics
}

\author{
M. T. Yilmaz,${ }^{* 1}$ E. Dertli, ${ }^{\star} †$ O. S. Toker, ${ }^{*}$ N. B. Tatlisu, $\ddagger$ O. Sagdic,${ }^{*}$ and M. Arici ${ }^{*}$ \\ *Yildiz Technical University, Chemical and Metallurgical Engineering Faculty, Food Engineering Department, 34210, Istanbul, Turkey \\ †Bayburt University, Engineering Faculty, Food Engineering Department, 69000, Bayburt, Turkey \\ †ístanbul Gelisim University, Vocational School, Food Technology Division, 34310, İstanbul, Turkey
}

\begin{abstract}
Exopolysaccharide (EPS)-producing starter cultures are preferred for the manufacture of fermented milk products to improve rheological and technological properties. However, no clear correlation exists between EPS production and the rheological and technological properties of fermented milk products such as the yogurt drink ayran. In this study, 4 different strain conditions (EPS $^{-}$and EPS ${ }^{+}$Streptococcus thermophilus strains) were tested as a function of incubation temperature $\left(32,37\right.$, or $\left.42^{\circ} \mathrm{C}\right)$ and time $(2,3$, or $4 \mathrm{~h})$ to determine the effect of culture type and in situ EPS production on physicochemical, rheological, sensory, and microstructural properties of ayran. Furthermore, we assessed the effect of fermentation conditions on amounts of EPS production by different EPS-producing strains during ayran production. A multifactorial design of response surface methodology was used to model linear, interaction, and quadratic effects of these variables on steady shear rheological properties of ayran samples and in situ EPS production levels. The physicochemical and microbiological characteristics of ayran samples altered depending on incubation conditions and strain selection. Steady shear tests showed that ayran samples inoculated with $\mathrm{EPS}^{+}$strains exhibited pseudoplastic flow behavior. Production of ayran with EPS ${ }^{-}$strain (control sample) resulted in the lowest apparent viscosity values $\left(\eta_{50}\right)$, whereas those produced with the combination of $2 \mathrm{EPS}^{+}$strains yielded ayran with notably increased $\eta_{50}$ values. We concluded that incubation time was the variable with the greatest effect on $\eta_{50}$, consistency coefficient $(K)$, and flow behavior index $(n)$ values. In situ EPS production was also affected by these conditions during ayran fermentation in which strain-specific metabolism conditions were found to be the most important factor for EPS production. In ad-
\end{abstract}

Received October 5, 2014.

Accepted November 2, 2014.

${ }^{1}$ Corresponding author: mtyilmaz@yildiz.edu.tr dition, these findings correlated the amount of in situ EPS produced with the rheological properties of ayran. Scanning electron microscopy images of the samples showed differences in structural features, revealing a prominent network strand structure in the ayran samples inoculated with the admixture of 2 EPS-producing strains incubated at $37^{\circ} \mathrm{C}$ for $3 \mathrm{~h}$. These results provide useful information for large-scale production of ayran by the dairy industry.

Key words: ayran, exopolysaccharide, rheology, optimization

\section{INTRODUCTION}

Demand is increasing worldwide for fermented dairy products because of their potential health-promoting properties, and these products have been traditionally produced in every country in the world. Ayran is a Turkish yogurt drink traditionally produced by adding water and salt to yogurt (homemade) or by addition of yogurt starter cultures to standardized milk for fermentation on an industrial scale with an annual production of approximately 1 million tonnes (Yildiz, 2009; Altay et al., 2013). The main technological problem in ayran is its tendency to exhibit rheological instability during storage similar to that of yogurt (it is a diluted yogurt product; Koksoy and Kilic, 2004; Ozdemir and Kilic, 2004). The rheological properties of ayran are affected by heat treatment of milk, DM, salt content of the final product, addition of transglutaminase, fermentation temperature, and final $\mathrm{pH}$, as well as starter culture type, such as ropy and nonropy starters (Köksoy and Kılıç, 2003, 2004; Ozdemir and Kilic, 2004; TamucayÖzünlü and Kocak, 2010a; Sanli et al., 2011). Similarly, use of stabilizers is reported to enhance the rheological properties of ayran although such use is not preferred because of their potential negative effect on the overall acceptability of fermented milk beverages (Koksoy and Kilic, 2004).

Several lactic acid bacteria (LAB) have been shown to produce exopolysaccharides (EPS) that may be at- 
tached to the bacterial cell wall or directly secreted to the environment. Lactic acid bacteria can structurally produce homopolysaccharides, which contain only one type of sugar molecule, and heteropolysaccharides, which are composed of different sugar monomers (Dertli et al., 2013). Exopolysaccharides have unique characteristics because of the differences in the sugar subunits and glycosidic linkages present in their repeating units, which explains the great diversity among bacterial EPS and novel EPS structures (De Vuyst and Degeest, 1999; Dertli et al., 2013).

Exopolysaccharides have crucial roles in physicochemical and rheological properties of fermented dairy products as natural bio-thickening agents and in situproduced stabilizers (Duboc and Mollet, 2001). Moreover, higher viscosity values are reported for fermented milk products, including yogurt, when EPS-producing cultures are used in fermentation compared with nonEPS-producing cultures (Marshall and Rawson, 1999; Folkenberg et al., 2006). These EPS were reported to enhance the sensory characteristics, including mouthfeel, shininess, ropiness, and creaminess, in which the characteristics of EPS play an important role (Folkenberg et al., 2005; Purwandari et al., 2007). In addition to their potential role on the improvement of the rheological properties of yogurt and fermented dairy products, their GRAS (generally regarded as safe) status also increased the interest in these biopolymers (De Vuyst and Degeest, 1999; Hassan et al., 2003a).

Several factors, including monosaccharide composition, linkage type, side chains, net charge, molecular weight of EPS, and their interaction with milk constituents, especially proteins and ions, affect the rheological functions of these biopolymers in fermented milk products (Kleerebezem et al., 1999; Duboc and Mollet, 2001; Ruas-Madiedo et al., 2002a; Broadbent et al., 2003; Hassan et al., 2003a). Similarly, the degree and length of branches in EPS molecules can significantly affect the compactness of the EPS, which determines their rheological role (Duboc and Mollet, 2001). In situ EPS production level was also among the factors having the most remarkable effect on rheological properties. However, previous reports showed that EPS concentration was not always positively correlated with yogurt viscosity, and that production of EPS might not always result in improved viscosity or gel firmness (Rawson and Marshall, 1997; Ruas-Madiedo et al., 2002a). It has also been reported that no difference was detected in the viscosity values of ayran samples produced with ropy and nonropy cultures (Ozdemir and Kilic, 2004). These contrary results might be due to the alterations in protein-EPS interactions during yogurt and ayran fermentation process that depend on final EPS structure and production levels as well as the chemical com- position of the final product, which can be affected by the starter culture type, incubation temperature, and time. However, these studies have been performed with a limited number of bacterial cultures and under different conditions, which makes it hard to compare these results directly with those noted previously (Folkenberg et al., 2006). Thus, to fully understand the role of EPS in the rheology of dairy products such as ayran, a comprehensive study is required to test the relationship between EPS production and culture incubation conditions and the chemical properties of these products along with their microstructural properties.

Several strategies exist to test the relationship between EPS production and culture incubation conditions and between amount of EPS produced and rheological properties. One of the most effective ways to do this is to determine the factors having the greatest effect on the fermentation process and to find the optimum or limit values of these factors. Given the production steps of fermented milk products and yogurt, incubation temperature and time appear to be among the most effective parameters in EPS production. To find the optimum or limit values of these factors, response surface methodology (RSM) is known to be a useful statistical tool, allowing improvement and optimization of processes by finding the experimental relationship between the input and output variables considered in the experimental design (Hejazi et al., 2012). Accurate assessment of the effect of factors relies, to a large extent, on determination of the simultaneous effects of multiple factors, as opposed to conclusions based on a single factor. However, in the literature, a considerable number of studies based on RSM have been conducted using an approach with a single-response problem and only limited attention has been given to multi-response problems. However, to achieve the best EPS-producing conditions in our case, a multiple-response optimization study should be conducted. To the best of our knowledge, a limited number of studies have been conducted on optimization of fermentation conditions for EPS production and effect of EPS amounts on rheological properties of fermented milk products based on multiple response optimization (Kimmel et al., 1998; Erkaya et al., 2014). Furthermore, no study has investigated the effect of in situ EPS production on rheological properties of ayran, a yogurt drink. Therefore, the objectives of this study were (1) to use RSM to determine the effect of fermentation conditions (incubation temperature and time) on in situ EPS production levels in ayran; (2) to investigate the effect of in situ EPS production on physicochemical, rheological, sensory, and microstructural properties of ayran; and (3) to determine if a correlation exists between the amount of EPS produced and rheological properties of ayran. 


\section{MATERIALS AND METHODS}

\section{Materials}

Standardized cow milk (pH 6.6, DM and fat of 8 and $2 \%$, respectively) was used for the preparation of ayran samples. The following strain conditions were used: (1) EPS $^{-}$strain (non-EPS-producing Streptococcus thermophilus strain) as control; (2) strain 1, an EPSproducing $S$. thermophilus strain (YO-MIX 499 LYO 100 DCU, Danisco Canada Inc., Scarborough, Canada); (3) strain 2, an EPS-producing S. thermophilus strain (YOG CY-340 DSL, Delvo, Delvo-Yog, DSM, Heerlen, the Netherlands); and (4) a mixture of strains 1 and 2. All strain conditions also included Lactobacillus delbrueckii ssp. bulgaricus in the starter culture.

\section{Ayran Production}

For ayran production, after the pasteurization $\left(85^{\circ} \mathrm{C}\right.$ for $15 \mathrm{~min}$ ) process, milk was cooled to the relevant incubation temperatures $\left(32,37\right.$, and $\left.42^{\circ} \mathrm{C}\right)$, as shown in Table 1, and each strain (EPS ${ }^{-}$strain, $2 \mathrm{EPS}^{+}$strains, and their mixture) was added at a $1 \%$ concentration. The samples were incubated at the relevant incubation times $(2,3$, and $4 \mathrm{~h})$ as presented in Table 1 . After incubation, the ayran samples were prepared with the addition of water (1:1), and then homogenized by using a mixer (Ultra Turrax, T18, IKA, Stauffen, Germany), and salt solution (1\%) was added as described previously (Ozdemir and Kilic, 2004). After homogenization, the ayran samples incubated at different incubation temperatures and times were stored at $4^{\circ} \mathrm{C}$ overnight until analysis.

\section{Physicochemical and Microbiological Analysis}

For the physicochemical analysis of ayran samples, $\mathrm{pH}$, percent $\mathrm{DM}$, fat and protein contents, and titrat- able acidity values were determined. The $\mathrm{pH}$ values were determined at $25^{\circ} \mathrm{C}$ using a pH meter (WTW 315i Set Model, Weilheim, Germany). To determine percent $\mathrm{DM}$ content, ayran samples were dried at $105^{\circ} \mathrm{C}$ for $4 \mathrm{~h}$ in a drying oven (Daihan, WOF sterilizator, Gangwondo, South Korea). Protein (micro-Kjeldahl method, $6.38 \times$ ) and fat contents (Gerber method) of ayran samples were determined using previously described methods (Yöney, 1973). Titratable acidity was determined after titrating with $0.1 \mathrm{~N} \mathrm{NaOH}$ and expressed as a percentage of lactic acid, as described previously (Metin, 2008). For the microbiological analysis of ayran samples, serial dilutions were prepared, plated onto M17 (Oxoid, Basingstoke, UK) and de Man, Rogosa, and Sharpe (MRS; Oxoid) plates, and incubated at $37^{\circ} \mathrm{C}$ for 48 and $72 \mathrm{~h}$ for enumeration of $S$. thermophilus and $L b$. delbrueckii ssp. bulgaricus counts, respectively.

\section{Isolation and Quantification of EPS in Ayran Samples}

For isolation of EPS from ayran samples, an equal volume of chilled ethanol was added to $20 \mathrm{~mL}$ of ayran sample followed by an overnight incubation at $4^{\circ} \mathrm{C}$. After centrifugation at $6,000 \times g$ for $30 \mathrm{~min}$ at $4^{\circ} \mathrm{C}$, the formed pellets containing EPS were resuspended in $5 \mathrm{~mL}$ of distilled water. For removal of proteins, TCA was added at a final concentration of $20 \%$ and the suspension was further incubated for $2 \mathrm{~h}$ at $4^{\circ} \mathrm{C}$ under gentle agitation. Precipitated proteins were removed by centrifugation at $13,000 \times g$ for $20 \mathrm{~min}$ at $4^{\circ} \mathrm{C}$, and supernatants were collected. Two volumes of cold ethanol were added to the supernatants for EPS precipitation, and the centrifugation process was followed as described above. The resuspended EPS were dialyzed (12,000-14,000-Da visking dialysis membrane, Medicell International, London, UK) against $5 \mathrm{~L}$ of distilled water for $2 \mathrm{~d}$ by changing the water 3 times per day. After isolation of EPS from ayran samples,

Table 1. The design matrix indicating the levels of coded and actual values for each run

\begin{tabular}{|c|c|c|c|c|}
\hline \multirow[b]{2}{*}{ Run } & \multicolumn{2}{|c|}{ Coded levels of factors } & \multicolumn{2}{|c|}{ Actual levels of factors } \\
\hline & $\begin{array}{c}\text { Incubation } \\
\text { temperature }\left({ }^{\circ} \mathrm{C}\right)\end{array}$ & $\begin{array}{l}\text { Incubation } \\
\text { time }(\mathrm{h})\end{array}$ & $\begin{array}{c}\text { Incubation } \\
\text { temperature }\left({ }^{\circ} \mathrm{C}\right)\end{array}$ & $\begin{array}{l}\text { Incubation } \\
\text { time }(\mathrm{h})\end{array}$ \\
\hline $\mathrm{R} 1$ & -1 & -1 & 32 & 2.0 \\
\hline $\mathrm{R} 2$ & -1 & 0 & 32 & 3.0 \\
\hline R3 & -1 & 1 & 32 & 4.0 \\
\hline $\mathrm{R} 4$ & 0 & -1 & 37 & 2.0 \\
\hline $\mathrm{R} 5$ & 0 & 0 & 37 & 3.0 \\
\hline R6 & 0 & 0 & 37 & 3.0 \\
\hline $\mathrm{R} 7$ & 0 & 1 & 37 & 4.0 \\
\hline $\mathrm{R} 8$ & 1 & -1 & 42 & 2.0 \\
\hline $\mathrm{R} 9$ & 1 & 0 & 42 & 3.0 \\
\hline $\mathrm{R} 10$ & 1 & 1 & 42 & 4.0 \\
\hline
\end{tabular}


EPS levels in each sample were determined by using the phenol-sulfuric acid method (DuBois et al., 1956) and expressed as milligrams of EPS per liter of sample.

\section{Steady Shear Rheological Analysis}

A strain/stress controlled rheometer (MRC 302, Anton Paar, Graz, Austria) equipped with a Peltier temperature controller was used to determine steady shear rheological characteristics of ayran samples. The measurements were carried out using a parallel plate configuration (plate diameter $35 \mathrm{~mm}$, angle $4^{\circ}$, gap size $0.5 \mathrm{~mm}$ ) in the shear rate range of 0.1 to $100 \mathrm{~s}^{-1}$ at a constant measurement temperature $\left(5^{\circ} \mathrm{C}\right)$. A $1.0-\mathrm{mL}$ sample was placed between plates, and measurement was started immediately. In total, 25 data points were recorded at 10-s intervals during the shearing. Each measurement was replicated 3 times in 2 different samples. Apparent viscosity was determined as a function of shear rate, and shear stress versus shear rate was plotted by increasing shear rate. The obtained data were fitted to the Ostwald de Waele model using Toolmaster (Graz, Austria), and consistency coefficient and flow behavior index values were calculated according to the following model used to describe shear-induced behavior of the ayran samples:

$$
\sigma=K \dot{\gamma}^{n}
$$

where $\sigma$ is the shear stress $(\mathrm{Pa}), K$ is the consistency coefficient $\left(\mathrm{Pa} \cdot \mathrm{s}^{n}\right), \dot{\gamma}$ is the shear rate $\left(\mathrm{s}^{-1}\right)$, and $n$ is the flow behavior index (dimensionless).

\section{Sensory Analysis}

The sensory analysis of ayran samples were determined based on protocol described previously (Yilmaz et al., 2011). In brief, 100-mL ayran samples were presented and served in coded glass containers to a panel consisting 5 women and 5 men. Panelists were trained before evaluation to familiarize them with the sensory analysis, samples, and methodology. All coded ayran samples were evaluated for color, odor, appearance, taste, viscosity, and general acceptance properties in a scale from 1 to 9 describing low to high acceptability, respectively.

\section{Scanning Electron Microscopy}

Microscopic structure of the ayran samples was analyzed by scanning electron microscopy. Samples were examined under high vacuum in a field emission scanning electron microscope (JSM-5510, JEOL Ltd.,
Tokyo, Japan) with a working distance of $8 \mathrm{~mm}$. Secondary electron images were acquired at an accelerating voltage of $5 \mathrm{kV}$. For processing of the images, SEM Control User Interface (version 5.21; JEOL Ltd.) was used.

\section{Data Analysis, Modeling, and Optimization}

Response surface methodology was performed to determine changes in the amount of EPS production and rheological parameters of ayran as a function of incubation temperature and time. For this purpose, a 3-level, 2-variable central composite design was used. The 2 factors, levels, and experimental design in terms of coded and uncoded (actual values) are given in Table 1. The model used was

$$
Y-\varepsilon=\beta_{0}+\sum_{i=1}^{N} \beta_{i} x_{i}+\sum_{i=1}^{N} \beta_{i i} x_{i}^{2}+\sum_{\substack{i=1 \\ i<j}} \sum_{j=i+1} \beta_{i j} x_{i} x_{j}, \quad[2]
$$

where $Y$ is the corresponding predicted response value, $\varepsilon$ is the error term, $\beta_{0}$ is the intercept term, $\beta_{i}$ is the linear term, $\beta_{i i}$ is the quadratic term, $\beta_{i j}$ is the interaction term, and $X_{i}$ and $X_{j}$ are the coded levels of the independent variables. The regression coefficients of linear, quadratic and interaction terms were determined by using Design Expert package software (version 7.0; Stat-Ease Inc., Minneapolis, MN) for each output parameter.

The best fitting models were determined using multiple linear regressions with backward elimination regression, in which insignificant factors and interactions were removed from the models and only the variables significant at $P<0.01, P<0.05$, and $P<0.1$ levels were selected for the model construction using backward elimination regression. For this procedure, let the model with all possible covariates be

$$
Y=\beta_{0}+\beta_{1} X_{1}+\ldots+\beta_{r-1} X_{r-1}+\varepsilon .
$$

Then, the following $r-1$ tests were carried out: $H_{0 j}$ : $\beta_{j}=0, j=1,2, \ldots, r-1$. The lowest partial $F$-test value $F_{l}$ corresponding to $H_{0 l}: \beta_{l}=0$ or $t$-test value $t_{l}$ is compared with the preselected significance values $F_{0}$ and $t_{0}$.

In this study, both single and multiple response optimization procedures were performed. Single response optimization is useful for finding the optimum values of factors for only one response. However, for industrial applications, optimization should be synchronously performed for all the responses involved. Moreover, competition occurs between these responses in many 
cases; thus, improving one response may lead another response to deteriorate, further complicating the situation. To overcome this problem, multiple responses are solved through use of a desirability function that combines all the responses into one measurement. The operating conditions, where $x$ provides the "most desirable" response values, can be found by this method. In this respect, different desirability functions $d_{i}\left(Y_{i}\right)$ can be used depending on whether a particular response $Y_{i}$ is to be maximized or minimized (Derringer and Suich, 1980). Let $L_{i}, U_{i}$, and $T_{i}$ be the lower, upper, and target values, respectively, that are desired for response $Y_{i}$ with $L_{i}, U_{i}$, and $T_{i}$.

If a response is to be maximized, then its individual desirability function is with the exponent $s$ that determines how significant it is to hit the target value. For $s=1$, the desirability function increases linearly toward $T_{i}$, which indicates a large adequate value for the response; for $s<1$, the function is convex, and for $s>1$, the function is concave:

$$
d_{i}\left(\hat{y}_{i}\right)=\left\{\begin{array}{cc}
0 & \hat{y}_{i}(x)<L_{i} \\
\left(\frac{\hat{y}_{i}(x)-L_{i}}{T_{i}-L_{i}}\right)^{2} & L_{i} \leq \hat{y}_{i}(x) \leq T_{i} . \\
1 & \hat{y}_{i}(x)>T_{i}
\end{array}\right.
$$

If a response is to be minimized, then its individual desirability function is with $T_{i}$, which indicates a small adequate value for the response:

$$
d_{i}\left(\hat{y}_{i}\right)=\left\{\begin{array}{cc}
1 & \hat{y}_{i}(x)<T_{i} \\
\left(\frac{\hat{y}_{i}(x)-U_{i}}{T_{i}-U_{i}}\right)^{2} & T_{i} \leq \hat{y}_{i}(x) \leq U_{i} . \\
0 & \hat{y}_{i}(x)>U_{i}
\end{array}\right.
$$

Having computed for each response variable, desirability values were combined into a single desirability index, $D$. For this purpose, each response was transformed in a dimensionless function, called partial desirability function, $d_{i}$, which reflects the desirable ranges for each response. The desirable ranges varies from 0 to 1 (least to most desirable, respectively. Definition of the partial desirability functions allows the global desirability function $D$ to calculate the weighted geometric mean of $n$ individual desirability functions (all transformed responses) [Eq. (6)]. The simultaneous objective function is a geometric mean of all transformed responses (Myers and Montgomery, 1995):

$$
D=\left(d_{1}^{p_{1}} \times d_{2}^{p_{2}} \times d_{3}^{p_{3}} \times \ldots \times d_{n}^{p_{i}}\right)^{1 / \sum p_{i}}=\left[\prod_{i=1}^{n} d_{i}^{p_{i}}\right]^{1 / \sum p_{i}},[6]
$$

where $p_{\mathrm{i}}$ is the weighting of the $i$ th desirability function, and normalized so that $\sum_{i=1}^{n} p_{i}=1$. By weighting the partial desirability functions, it is possible to enable the optimization process to take the relative importance of each response into consideration. By examining the form of the desirability function, it is possible to find the region where the function was close to 1 and determine the compromise optimum conditions.

The computational work including designation of experimental points, randomization, ANOVA, fitting of the second-order polynomial models, graphical representations, and optimization was performed using the statistical package Design Expert (version 7.0; StatEase Inc.). The SPSS Statistics package (17.0; SPSS Statistics/IBM, Armonk, NY) was used to conduct an ANOVA to show the differences between experimental runs and between treatments $(P<0.05)$.

\section{RESULTS AND DISCUSSION}

The effects of strain selection as a function of EPS production as well as incubation temperature and time on chemical properties of the ayran samples are presented in Table 2. The final $\mathrm{pH}$ of ayran after incubation period is critical in terms of the development of a desired final product due to its role in chemical, physicochemical, and rheological properties of ayran (Tamucay-Özünlü and Kocak, 2010b). Our study revealed that the $\mathrm{pH}$ values of ayran samples were significantly affected $(P<0.05)$ both by starter culture type with different EPS production characteristics and by fermentation temperature and time, and several trends were observed. As expected, ayran samples achieved lower $\mathrm{pH}$ values when the incubation temperature and time were increased from $32^{\circ} \mathrm{C}$ to $42^{\circ} \mathrm{C}$ and from 2 to $4 \mathrm{~h}$, respectively. Similar observations have been reported during yogurt production (Purwandari et al., 2007). The $\mathrm{pH}$ of ayran samples ranged between 4.78 and 3.94 for all strain conditions depending on the incubation temperature and time (Table 2). Similar to our results, the $\mathrm{pH}$ of ayran samples is reported to range between 3.96 and 4.52 on the first day of incubation (Tamucay-Özünlü and Kocak, 2010a; Sanli et al., 2011). In general, the effect of incubation time on alterations of $\mathrm{pH}$ values of ayran samples was greater than that of incubation temperature. Previously, $2 S$. thermophilus strains were compared for their fermentation time required to reach $\mathrm{pH} 4.5$ in yogurt samples 
depending on incubation temperature and this time was found to be different due to the thermophilic or mesophilic character of the strains (Purwandari et al., 2007). We cannot clearly correlate the $\mathrm{pH}$ differences with the temperature requirements of the strains tested, which could be because of the short incubation period used in our study. Importantly, strain type, with different EPS production characteristics, affected the $\mathrm{pH}$ values of ayran samples, and the lowest $\mathrm{pH}$ values were detected in the EPS ${ }^{-}$control group, a finding in agreement with previous observations where nonropy cultures more rapidly decreased the final $\mathrm{pH}$ of ayran samples than did ropy cultures. Final pH of ayran is reported to be important for ayran rheology (Ozdemir and Kilic, 2004). In fact, this is expected because EPS production is an energy-intensive process (Broadbent et al., 2003) and the catabolic mechanism of the nonEPS-producing strain might be faster than that of EPS-producing strains, which may result in more lactic acid formation and a greater reduction in final $\mathrm{pH}$. The higher titratable acidity values $(P<0.05)$ of the control ayran group compared with the other groups may also support this observation (Table 2). We also observed some significant differences $(P<0.05)$ in $\mathrm{pH}$ of ayran samples produced with EPS-producing strains that could be related to strain-specific conditions. It has been reported that a slimy EPS-producing strain $S$. thermophilus showed a faster decrease in $\mathrm{pH}$ of yogurt samples compared with a capsular EPS-producing strain (Purwandari et al., 2007).

The DM content of ayran samples was also affected by inoculation and incubation conditions and varied between 6.98 and $6.42 \%$. Generally, a short incubation period resulted in higher DM content and incubation period on DM content of ayran was more likely to be important than the type of strain used in ayran production at each incubation temperature. For instance in the first, second, and third runs (in which ayran was produced at $32^{\circ} \mathrm{C}$ ), we found no significant difference in DM content of ayran samples, but different incubation periods resulted in significant differences for different strains $(P<0.05$; control and strain mixture groups). Similar trends were observed for other conditions tested. The DM values of ayran samples in our study were similar to previous observations (Gülmez et al., 2003). Another important chemical characteristic of dairy products such as ayran is their fat content. Similar to DM content, we did not observe large fluctuations in the fat contents of ayran samples. No significant differences were detected for different EPS-producing strains except in runs 4, 5, and 10 (Table 2). Similarly, we did not detect a linear relationship between incubation temperature and time and the fat content of ayran samples, although several trends observed. The high- est and lowest fat contents were found to be 2.00 and $1.70 \%$, respectively, for all ayran samples tested, which was in accordance with previous observations (Gülmez et al., 2003). Additionally, the protein contents of ayran samples were evaluated and ranged between 1.73 and $2.07 \%$ (Table 2); protein content differed depending on the conditions tested. These alterations among different strain groups were found to be important $(P<$ 0.05), showing strain-specific effects on the fermentation process. These results were also in agreement with previous observations, in which the protein content of ayran samples was reported to be between 1.44 and $3.48 \%$ (Altay et al., 2013).

The titratable acidity values of ayran samples, expressed as the amount of lactic acid, were determined in this study for all conditions tested (Table 2). We noted significant alterations $(P<0.05)$ in acidity values of ayran samples among different groups depending on EPS production as well as different incubation temperatures and times. The acidity ranged between 0.49 and $0.73 \%$ for the ayran samples produced with strain 1 and between 0.41 and $0.76 \%$ for the ayran samples produced with strain 2. Notably, the highest acidity values in ayran samples were detected in the control group and ranged between 0.58 and $0.90 \%$. This could be related to the faster growth and acidification rates in $\mathrm{EPS}^{-}$strains, as discussed above (De Vuyst and Degeest, 1999; Duboc and Mollet, 2001; Broadbent et al., 2003; Purwandari et al., 2007). The combination of 2 EPS-producing strains widened the range of acidity of ayran samples, which were found to be between 0.41 and $0.87 \%$. Our results were also in agreement with previous observations, in which the acidity of ayran samples was found to be between 0.2 and $1.0 \%$ (Gülmez et al., 2003; Tamucay-Özünlü and Kocak, 2010a; Sanli et al., 2011). Additionally, incubation conditions affected the acidity values of ayran samples; the increase in incubation temperature and time from 32 to $42^{\circ} \mathrm{C}$ and from 2 to $4 \mathrm{~h}$ increased acidity values in all treatment groups (Table 2). These observations were similar to alterations in the $\mathrm{pH}$ values of ayran sample.

We also evaluated the effect of EPS production and fermentation temperature and time on the initial counts of $S$. thermophilus and Lb. delbrueckii ssp. bulgaricus in all ayran samples, and these counts were clearly both dependent on inoculation and incubation conditions $(P$ $<0.05$, Table 2). We did not observe a clear correlation between the increase in incubation temperature and $S$. thermophilus counts but, in general, S. thermophilus counts increased with increasing incubation time. It was previously reported that the numbers of viable cells in yogurt are higher at 30 and $42^{\circ} \mathrm{C}$ than at $37^{\circ} \mathrm{C}$ and that counts of viable cells of ropy strain are permanently higher than that of capsular strain, regardless of incu- 
Table 2. Physicochemical and microbiological properties ${ }^{1}$ and exopolysaccharide (EPS) yield in ayran samples inoculated with different strains ${ }^{1}$

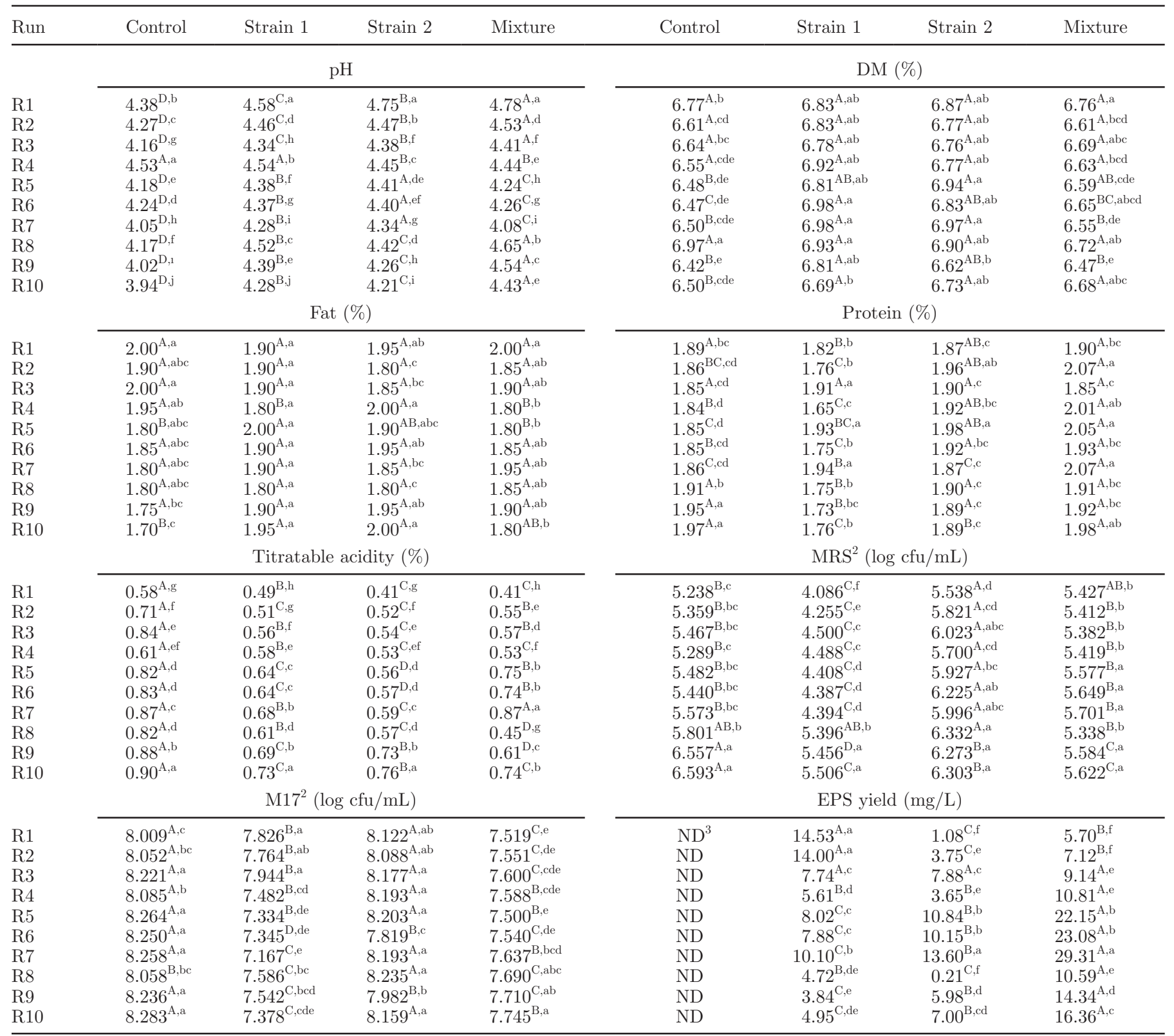

$\overline{\mathrm{A}-\mathrm{D}}$ Different uppercase superscript letters show differences between the strains within the same run $(P<0.05)$.

${ }^{\mathrm{a}-\mathrm{j} D i f f e r e n t}$ lowercase superscript letters show differences between runs within the same strain $(P<0.05)$.

${ }^{1}$ Control = non-EPS-producing Streptococcus thermophilus strain; strains 1 and $2=$ EPS-producing $S$. thermophilus strain; mixture $=$ admixture of strains 1 and 2 .

${ }^{2}$ Growth on M17 and de Man, Rogosa, and Sharpe (MRS) medium.

${ }^{3} \mathrm{ND}=$ not detected.

bation conditions (Purwandari et al., 2007). Our results also revealed that the numbers of $S$. thermophilus in ayran samples were dependent on strain characteristics $(P<0.05)$; however, we detected no clear dependency of $S$. thermophilus count on EPS production. In general, $S$. thermophilus counts of ayran samples produced with EPS $^{-}$strain and strain 2 and ayran samples produced with strain 1 and strain mixture, respectively, did not show significant differences $(P>0.05)$ and notably the amount of EPS produced under these conditions were significantly different $(P<0.05$, Table 2$)$. Similar results were previously reported, in which EPS production of $S$. thermophilus strains was dependent on the strain-specific conditions (Vaningelgem et al., 2004) 
and, for particular strains, growth-associated EPS production was also reported (De Vuyst et al., 1998). Notably, higher growth rates in LAB strains might not always reflect higher EPS production because both cell wall biosynthesis and EPS production require the availability of isoprenoid phosphate lipid carrier and sugar nucleotides (Whitfield, 1988). Our findings also revealed a trend between counts of $S$. thermophilus in ayran samples and chemical characteristics such as $\mathrm{pH}$ and titratable acidity, especially for the control group. In contrast to $S$. thermophilus numbers, increasing the incubation temperature significantly increased counts of Lb. delbrueckii ssp. bulgaricus in ayran samples ( $P$ $<0.05)$ and the same trend was observed with increasing the incubation temperature (Table 2). The highest and lowest counts of $L b$. delbrueckii ssp. bulgaricus were detected in ayran samples produced with strain 1 in the first run and with the control strain in the tenth run, respectively. Similarly, in general, the lowest counts of $L b$. delbrueckii ssp. bulgaricus were detected for ayran samples produced with strain 1 , in which $S$. thermophilus counts were also observed to be lower than in the other strain conditions (Table 2). The ratio of $S$. thermophilus to Lb. delbrueckii ssp. bulgaricus is important in terms of technological properties of ayran because of the limited proteolytic activities of S. thermophilus; the ratio in our study was lower than previous observations in ayran (Tamucay-Özünlü and Kocak, 2010a) but similar to that of reported for yogurt fermentation (Akın and Sıddık, 1999).

The analysis of in situ EPS production during ayran fermentation revealed that EPS production was significantly $(P<0.05)$ affected by incubation temperature and time and by strain-specific conditions (Table 2). For instance, the highest and lowest EPS production were observed in runs 1 and 9 , in runs 7 and 8 , and in runs 7 and 1 for ayran samples produced with strain 1 , strain 2 , and strain mixture, respectively (Table 2 ). At an incubation temperature of $32^{\circ} \mathrm{C}$, we observed no increase in EPS production with increasing incubation time when strain 1 was used but EPS production significantly $(P<0.05)$ increased for strain 2 and strain mixture with the increasing incubation period at this temperature; however, the highest EPS production was recorded for strain 1 after $2 \mathrm{~h}$ of incubation. Optimum EPS production temperature when the strain mixture was used was $37^{\circ} \mathrm{C}$; in general, maximum EPS yields were recorded for the strain mixture. This may explain the fact that the highest apparent viscosity values were recorded for ayran produced using the strain mixture (Table 3). However, the relationship between EPS yields and rheological parameters of ayran samples were not always clear and it has been reported previously that no clear relationship exists between EPS production and viscosity, especially when comparing different strains (Ruas-Madiedo et al., 2002; De Vuyst et al., 2003). At this temperature $\left(37^{\circ} \mathrm{C}\right)$, in situ EPS production during ayran production showed a consistent significant increase $(P<0.05)$ for all strain conditions tested. The highest EPS production in ayran was recorded at $37^{\circ} \mathrm{C}$ for the strain mixture, with a yield of $29.31 \mathrm{mg} / \mathrm{L}$. We should also note that neither chemical characteristics such as $\mathrm{pH}$ nor microbiological results demonstrated the highest number of $S$. thermophilus at this temperature. This may suggest that EPS production is not only related to intrinsic strain metabolism conditions but it can also be affected by extrinsic factors such as incubation conditions, which can alter the final EPS yields, monomer composition, and molecular mass of the final EPS (Grobben et al., 1997; De Vuyst et al., 1998; De Vuyst and Degeest, 1999; Dertli et al., 2013). At $42^{\circ} \mathrm{C}$, EPS production did not increase with the increasing incubation time for strain 1, but we did observe a significant increase $(P<0.05)$ in EPS production for the other 2 strain conditions with increasing incubation time (Table 2). Interestingly, the lowest EPS yield for all conditions tested was recorded for strain 2 at $42^{\circ} \mathrm{C}$ after a 2 -h incubation period, which was consistent with the low apparent viscosity value in this run (Table 3). Similar to the general EPS yields, EPS levels of the strain mixture were significantly higher $(P<$ 0.05) than those of the other strain conditions at this incubation temperature (Table 2). Several variations on EPS production were recorded for different strain conditions, which can be related to the biosynthesis mechanism of EPS in S. thermophilus, as this species produces heteropolymeric-type EPS, which may show genetic instability depending on environmental conditions (De Vuyst and Degeest, 1999; Duboc and Mollet, 2001; Broadbent et al., 2003).

Overall, in situ EPS production by different strains during ayran fermentation was determined by incubation and strain-specific conditions, and the effect of these conditions on final EPS yields was modeled by using RSM. Table 4 shows the $F$-values of model parameters generated for final EPS yields for ayran samples produced with strains 1 and 2 and the strain mixture. As can be seen in Table 4 , the $\mathrm{R}^{2}$ values for all strain conditions tested were close to 1 , suggesting that the models demonstrated sufficient predictability for EPS yields depending on the parameters tested. Results revealed that linear effects of both incubation temperature and time significantly $(P<0.01 ; P$ $<0.1)$ affected EPS production. Previous studies also reported the crucial role of incubation temperature and time on EPS yields of LAB strains (Petry et al., 2000; Broadbent et al., 2003; Tallon et al., 2003). In Figure 1 , these effects are illustrated as 3-dimensional response 
Table 3. Ostwald de Waele variables, $\eta_{0}$ values, and related determination coefficients $\left(\mathrm{R}^{2}\right)$ of ayran samples inoculated with different strains ${ }^{1}$

\begin{tabular}{|c|c|c|c|c|}
\hline $\begin{array}{l}\text { Variable }^{2} \\
\text { and run }\end{array}$ & Control & Strain 1 & Strain 2 & Mixture \\
\hline \multicolumn{5}{|l|}{$K\left(\mathrm{~Pa} \cdot \mathrm{s}^{n}\right)$} \\
\hline $\mathrm{R} 1$ & $0.550^{\mathrm{B}, \mathrm{f}}$ & $0.025^{\mathrm{D}, \mathrm{e}}$ & $0.159^{\mathrm{C}, \mathrm{f}}$ & $0.648^{\mathrm{A}, \mathrm{h}}$ \\
\hline $\mathrm{R} 2$ & $1.007^{\mathrm{B}, \mathrm{e}}$ & $0.109^{\mathrm{D}, \mathrm{e}}$ & $0.885^{\mathrm{C}, \mathrm{de}}$ & $1.236^{\mathrm{A}, \mathrm{g}}$ \\
\hline R3 & $1.091^{\mathrm{B}, \mathrm{e}}$ & $0.579^{\mathrm{C}, \mathrm{c}}$ & $1.034^{\mathrm{B}, \mathrm{d}}$ & $2.485^{\mathrm{A}, \mathrm{e}}$ \\
\hline $\mathrm{R} 4$ & $0.752^{\mathrm{B}, \mathrm{ef}}$ & $0.062^{\mathrm{D}, \mathrm{e}}$ & $0.323^{\mathrm{C}, \mathrm{ef}}$ & $0.950^{\mathrm{A}, \mathrm{gh}}$ \\
\hline R5 & $3.501^{\mathrm{B}, \mathrm{b}}$ & $0.414^{\mathrm{D}, \mathrm{cd}}$ & $1.049^{\mathrm{C}, \mathrm{de}}$ & $4.618^{\mathrm{A}, \mathrm{c}}$ \\
\hline $\mathrm{R} 6$ & $3.569^{\mathrm{B}, \mathrm{b}}$ & $0.369^{\mathrm{D}, \mathrm{cd}}$ & $1.176^{\mathrm{C}, \mathrm{d}}$ & $4.260^{\mathrm{A}, \mathrm{c}}$ \\
\hline R7 & $4.855^{\mathrm{A}, \mathrm{a}}$ & $1.433^{\mathrm{B}, \mathrm{b}}$ & $1.775^{\mathrm{B}, \mathrm{c}}$ & $5.365^{\mathrm{A}, \mathrm{b}}$ \\
\hline $\mathrm{R} 8$ & $1.644^{\mathrm{B}, \mathrm{d}}$ & $0.255^{\mathrm{D}, \mathrm{de}}$ & $0.500^{\mathrm{C}, \mathrm{def}}$ & $1.924^{\mathrm{A}, \mathrm{f}}$ \\
\hline R9 & $2.799^{\mathrm{B}, \mathrm{c}}$ & $1.220^{\mathrm{C}, \mathrm{b}}$ & $3.563^{\mathrm{A}, \mathrm{b}}$ & $3.767^{\mathrm{A}, \mathrm{d}}$ \\
\hline R10 & $3.013^{\mathrm{D}, \mathrm{c}}$ & $4.346^{\mathrm{C}, \mathrm{a}}$ & $8.384^{\mathrm{A}, \mathrm{a}}$ & $6.752^{\mathrm{B}, \mathrm{a}}$ \\
\hline \multicolumn{5}{|l|}{$\eta_{50}(\mathrm{~Pa} \cdot \mathrm{s})$} \\
\hline $\mathrm{R} 1$ & $0.040^{\mathrm{B}, \mathrm{i}}$ & $0.006^{\mathrm{D}, \mathrm{f}}$ & $0.028^{\mathrm{C}, \mathrm{h}}$ & $0.105^{\mathrm{A}, \mathrm{h}}$ \\
\hline $\mathrm{R} 2$ & $0.067^{\mathrm{D}, \mathrm{g}}$ & $0.116^{\mathrm{C}, \mathrm{d}}$ & $0.162^{\mathrm{B}, \mathrm{d}}$ & $0.220^{\mathrm{A}, \mathrm{e}}$ \\
\hline R3 & $0.069^{\mathrm{D}, \mathrm{g}}$ & $0.212^{\mathrm{B}, \mathrm{b}}$ & $0.182^{\mathrm{C}, \mathrm{c}}$ & $0.251^{\mathrm{A}, \mathrm{c}}$ \\
\hline $\mathrm{R} 4$ & $0.051^{\mathrm{B}, \mathrm{h}}$ & $0.043^{\mathrm{C}, \mathrm{e}}$ & $0.112^{\mathrm{A}, \mathrm{f}}$ & $0.118^{\mathrm{A}, \mathrm{g}}$ \\
\hline R5 & $0.107^{\mathrm{D}, \mathrm{d}}$ & $0.121^{\mathrm{C}, \mathrm{d}}$ & $0.178^{\mathrm{B}, \mathrm{e}}$ & $0.251^{\mathrm{A}, \mathrm{c}}$ \\
\hline R6 & $0.102^{\mathrm{D}, \mathrm{e}}$ & $0.124^{\mathrm{C}, \mathrm{d}}$ & $0.172^{\mathrm{B}, \mathrm{e}}$ & $0.248^{\mathrm{A}, \mathrm{c}}$ \\
\hline $\mathrm{R} 7$ & $0.115^{\mathrm{C}, \mathrm{c}}$ & $0.197^{\mathrm{B}, \mathrm{c}}$ & $0.186^{\mathrm{B}, \mathrm{b}}$ & $0.272^{\mathrm{A}, \mathrm{b}}$ \\
\hline $\mathrm{R} 8$ & $0.094^{\mathrm{C}, \mathrm{f}}$ & $0.126^{\mathrm{B}, \mathrm{d}}$ & $0.087^{\mathrm{D}, \mathrm{g}}$ & $0.161^{\mathrm{A}, \mathrm{f}}$ \\
\hline R9 & $0.127^{\mathrm{D}, \mathrm{b}}$ & $0.204^{\mathrm{B}, \mathrm{bc}}$ & $0.188^{\mathrm{C}, \mathrm{bc}}$ & $0.236^{\mathrm{A}, \mathrm{d}}$ \\
\hline R10 & $0.136^{\mathrm{D}, \mathrm{a}}$ & $0.264^{\mathrm{B}, \mathrm{a}}$ & $0.216^{\mathrm{C}, \mathrm{a}}$ & $0.293^{\mathrm{A}, \mathrm{a}}$ \\
\hline \multicolumn{5}{|l|}{$n$} \\
\hline $\mathrm{R} 1$ & $0.347^{\mathrm{C}, \mathrm{a}}$ & $0.662^{\mathrm{A}, \mathrm{e}}$ & $0.581^{\mathrm{B}, \mathrm{b}}$ & $0.562^{\mathrm{B}, \mathrm{a}}$ \\
\hline $\mathrm{R} 2$ & $0.325^{\mathrm{C}, \mathrm{a}}$ & $1.007^{\mathrm{A}, \mathrm{a}}$ & $0.578^{\mathrm{B}, \mathrm{b}}$ & $0.555^{\mathrm{B}, \mathrm{a}}$ \\
\hline R3 & $0.307^{\mathrm{D}, \mathrm{ab}}$ & $0.742^{\mathrm{A}, \mathrm{d}}$ & $0.558^{\mathrm{B}, \mathrm{bc}}$ & $0.423^{\mathrm{C}, \mathrm{c}}$ \\
\hline $\mathrm{R} 4$ & $0.326^{\mathrm{D}, \mathrm{a}}$ & $0.924^{\mathrm{A}, \mathrm{b}}$ & $0.730^{\mathrm{B}, \mathrm{a}}$ & $0.456^{\mathrm{C}, \mathrm{b}}$ \\
\hline R5 & $0.123^{\mathrm{D}, \mathrm{d}}$ & $0.641^{\mathrm{A}, \mathrm{e}}$ & $0.551^{\mathrm{B}, \mathrm{cd}}$ & $0.276^{\mathrm{C}, \mathrm{ef}}$ \\
\hline R6 & $0.140^{\mathrm{D}, \mathrm{d}}$ & $0.553^{\mathrm{A}, \mathrm{e}}$ & $0.478^{\mathrm{B}, \mathrm{d}}$ & $0.298^{\mathrm{C}, \mathrm{e}}$ \\
\hline R7 & $0.079^{\mathrm{D}, \mathrm{e}}$ & $0.501^{\mathrm{A}, \mathrm{f}}$ & $0.412^{\mathrm{B}, \mathrm{e}}$ & $0.263^{\mathrm{C}, \mathrm{f}}$ \\
\hline $\mathrm{R} 8$ & $0.281^{\mathrm{D}, \mathrm{b}}$ & $0.816^{\mathrm{A}, \mathrm{c}}$ & $0.572^{\mathrm{B}, \mathrm{b}}$ & $0.369^{\mathrm{C}, \mathrm{d}}$ \\
\hline R9 & $0.210^{\mathrm{D}, \mathrm{c}}$ & $0.548^{\mathrm{A}, \mathrm{f}}$ & $0.261^{\mathrm{C}, \mathrm{f}}$ & $0.300^{\mathrm{B}, \mathrm{e}}$ \\
\hline R10 & $0.221^{\mathrm{B}, \mathrm{c}}$ & $0.301^{\mathrm{A}, \mathrm{g}}$ & $0.081^{\mathrm{C}, \mathrm{g}}$ & $0.191^{\mathrm{B}, \mathrm{g}}$ \\
\hline \multicolumn{5}{|l|}{$\mathrm{R}^{2}$} \\
\hline $\mathrm{R} 1$ & 0.9991 & 0.9899 & 0.9774 & 0.9227 \\
\hline $\mathrm{R} 2$ & 0.9938 & 0.9750 & 0.9881 & 0.9754 \\
\hline R3 & 0.9893 & 0.9884 & 0.9877 & 0.9934 \\
\hline $\mathrm{R} 4$ & 0.9985 & 0.9698 & 0.9975 & 0.9693 \\
\hline R5 & 0.9206 & 0.9893 & 0.9943 & 0.9957 \\
\hline $\mathrm{R} 6$ & 0.9625 & 0.9810 & 0.9859 & 0.9961 \\
\hline R7 & 0.8107 & 0.9791 & 0.9860 & 0.9949 \\
\hline $\mathrm{R} 8$ & 0.9792 & 0.9928 & 0.9975 & 0.9569 \\
\hline R9 & 0.9729 & 0.9874 & 0.9780 & 0.9751 \\
\hline R10 & 0.9736 & 0.9947 & 0.8549 & 0.9654 \\
\hline
\end{tabular}

surfaces, in which the direction of the effects of incubation temperature and time on EPS production for all ayran strains and the second-order regression model equations can be seen. These graphs show that final EPS yields in all 3 strain conditions increased with the increase in incubation time. Similarly, incubation temperature had a positive effect on EPS yields for strain 2 and the mixture but had a negative effect for strain 1, in which the effect of incubation temperature was the most determining factor for EPS production. Further- more, the quadratic effect of incubation temperature was found to be the most determinant factor for strain 2 and the strain mixture in EPS production, suggesting an optimum incubation temperature for EPS production during fermentation process (Figure 1). Previous reports revealed the complex relationship between the EPS production of LAB and incubation temperature, in which it was suggested that EPS production is maximal when the incubation temperature is lower than the optimum growth temperature. This finding is related to 
Strain 1

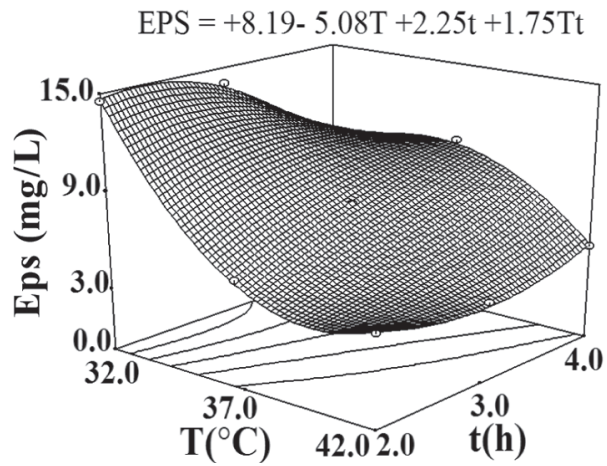

Strain 2

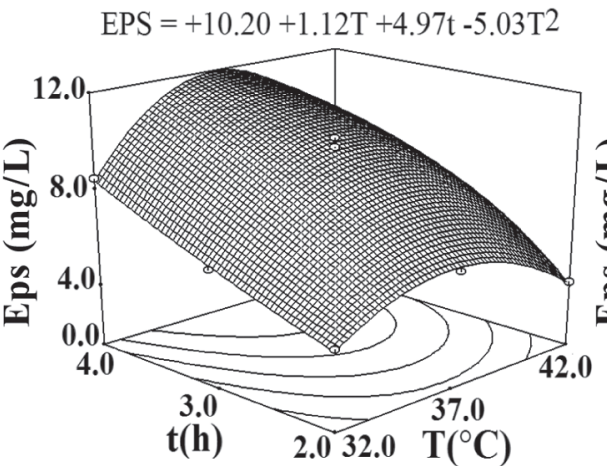

Mixture

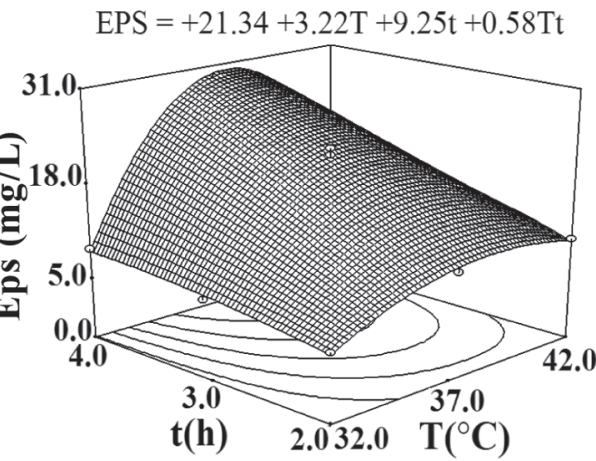

Figure 1. Effect of incubation temperature $(\mathrm{T})$ and time $(\mathrm{t})$ on amounts of exopolysaccharide (EPS) production by different EPS-producing strains in ayran samples. Strains 1 and $2=$ EPS-producing Streptococcus thermophilus strains; mixture = admixture of strains 1 and 2.

Table 4. Significance of the regression models ( $F$ values) and effects of the processing variables ${ }^{1}$ on rheological properties and exopolysaccharide (EPS) yield in ayran samples inoculated with different strains ${ }^{2}$

\begin{tabular}{|c|c|c|c|c|c|c|c|c|}
\hline Factor & Control & Strain 1 & Strain 2 & Mixture & Control & Strain 1 & Strain 2 & Mixture \\
\hline Mode & Modified & Quadratic & Quadratic & Quadratic & Modified & $2 \mathrm{FI}^{3}$ & Quadratic & Quadratic \\
\hline$x_{1}$ (temperature) & $52.45^{* *}$ & $357.34^{* *}$ & $68.87 * *$ & $21.33^{* *}$ & $21.87 * *$ & $5.68 \dagger$ & $69.97 * *$ & $36.05^{* *}$ \\
\hline$x_{2}$ (time) & $114.59^{* *}$ & $650.80^{* *}$ & $131.23^{* *}$ & $38.98^{* *}$ & $56.71^{* *}$ & $7.50^{*}$ & $74.92^{* *}$ & $23.94^{* *}$ \\
\hline$x_{1} x_{2}$ & - & 1.00 & 4.30 & 0.025 & - & $5.40 \dagger$ & $35.67^{* *}$ & 2.28 \\
\hline$x_{1}^{2} x_{2}$ & $44.98^{* *}$ & - & - & - & $24.10^{* *}$ & - & - & - \\
\hline$x_{1} x_{2}^{2}$ & - & - & - & - & - & - & - & - \\
\hline Lack of fit & 41.63 & 67.24 & 10.30 & 32.43 & 4.79 & 1.45 & 0.43 & 6.93 \\
\hline $\mathrm{R}^{2}$ & 0.9848 & 0.9961 & 0.9821 & 0.9440 & 0.9739 & 0.7560 & 0.9804 & 0.9436 \\
\hline Adjusted $\mathrm{R}^{2}$ & 0.9658 & 0.9911 & 0.9598 & 0.8739 & 0.9413 & 0.6339 & 0.9559 & 0.8732 \\
\hline Predicted $\mathrm{R}^{2}$ & 0.8454 & 0.9677 & 0.8243 & 0.5783 & 0.6633 & 0.1126 & 0.8634 & 0.6249 \\
\hline$x_{1}($ temperature $)$ & $63.03^{* *}$ & $16.49^{*}$ & $4.91 \dagger$ & $9.17^{*}$ & - & $254.43^{* *}$ & $5.71^{* *}$ & $15.44 \dagger$ \\
\hline$x_{2}($ time $)$ & $34.63^{* *}$ & $38.55^{* *}$ & $44.15^{* *}$ & $114.81^{* *}$ & - & $49.72^{*}$ & 113.45 & $101.37^{* *}$ \\
\hline$x_{1} x_{2}$ & 0.50 & $13.40^{*}$ & 0.33 & 2.31 & - & $60.66^{*}$ & 0.0001 & 0.80 \\
\hline$x_{1} x_{1}$ & 0.13 & 0.017 & 0.68 & 0.034 & - & 2.79 & $135.57^{* *}$ & $154.92^{* *}$ \\
\hline$x_{2} x_{2}$ & $6.93 \dagger$ & 3.68 & $6.95 \dagger$ & $19.17^{*}$ & - & 3.82 & $8.61 \dagger$ & 2.19 \\
\hline$x_{1}^{2} x_{2}$ & - & - & - & - & - & $99.13^{* *}$ & 7.60 & $38.14^{*}$ \\
\hline$x_{1} x_{2}^{2}$ & - & - & - & - & - & $24.54^{*}$ & 7.38 & 0.27 \\
\hline Lack of fit & 9.44 & 68.70 & 35.32 & 141.67 & - & 40.76 & 2.65 & 6.81 \\
\hline $\mathrm{R}^{2}$ & 0.9636 & 0.9475 & 0.9355 & 0.9734 & - & 0.9968 & 0.9949 & 0.9938 \\
\hline Adjusted $\mathrm{R}^{2}$ & 0.9180 & 0.8818 & 0.8548 & 0.9401 & - & 0.9855 & 0.9769 & 0.9720 \\
\hline Predicted $\mathrm{R}^{2}$ & 0.6298 & 0.4519 & 0.3265 & 0.7468 & - & 0.5574 & 0.4710 & 0.2356 \\
\hline Adequate precision & 14.572 & 11.538 & 9.339 & 14.486 & - & 27.413 & 23.429 & 21.156 \\
\hline
\end{tabular}

${ }^{1} K=$ consistency coefficient; $\eta_{50}=$ apparent viscosity; $n=$ flow behavior index.

${ }^{2}$ Control = non-EPS-producing Streptococcus thermophilus strain; strains 1 and $2=$ EPS-producing $S$. thermophilus strain; mixture = admixture of strains 1 and 2 .

${ }^{3}$ Two-factor interaction.

${ }^{4}$ The ratio of maximum response to minimum was $>10$; the data were analyzed after base 10 log-transformation was performed.

$\dagger P<0.10 ;{ }^{*} P<0.05 ;{ }^{* *} P<0.01$. 
the lesser formation of cell wall at lower temperatures, which means the availability of more sugar nucleotides for EPS production (Sutherland, 1972; van den Berg et al., 1995); in another study, however, the optimum growth temperature was reported to be the optimum temperature for EPS production (Kojic et al., 1992). Our results suggest that selection of incubation temperature depending on strain-specific conditions with regard to EPS production is crucial to improve the final quality of ayran.

Figure 2 shows the shear rate versus shear stress data for ayran samples produced under different inoculation and incubation conditions. As can be seen, the apparent viscosity of ayran samples produced with all strain conditions decreased depending on the shear rate, indicating that all ayran samples showed shear thinning behavior. Importantly, both inoculation and incubation conditions affected the rheological conditions of ayran samples but the latter were more important for the determination of ayran rheology (Figure 2). The obtained shear rate versus shear stress data for all ayran samples were fitted to an Ostwald de Waele model and model parameters were determined for all conditions tested. The model parameters and the apparent viscosity values measured at $50 \mathrm{~s}^{-1}\left(\boldsymbol{\eta}_{50}\right)$ for all ayran samples are presented in Table 4. As can be seen in Table 4, the coefficient of determination values $\left(\mathrm{R}^{2}\right)$ for the Ostwald de Waele model of ayran samples produced with the control strain, strains 1 and 2, and strain mixture ranged between 0.8107 and $0.9991,0.9698$ and 0.9947 , 0.8549 and 0.9975 , and 0.9227 and 0.9961 , respectively. The closeness of the $R^{2}$ values to 1 show that this model successfully determined the flow behavior of ayran samples. The apparent viscosity of ayran samples significantly increased $(P<0.05)$ with increasing incubation temperature and time for all strain conditions. For instance, the highest $\eta_{50}$ values were detected at $42^{\circ} \mathrm{C}$ after $4 \mathrm{~h}$ of incubation for all strains. The increase in the $\eta_{50}$ values of ayran with increasing fermentation temperature were also reported for both ropy and nonropy strains and it was suggested that the increase in the hydrophobic interactions of proteins at higher incubation temperatures could explain the increased $\eta_{50}$ values in ayran (Ozdemir and Kilic, 2004). Similarly, the effect of incubation time on $\eta_{50}$ values of ayran might be related to increasing cross-linkages in the protein network but this process can be determined by several factors other than incubation time, including chemical characteristics such as $\mathrm{pH}$ and acidification rates and EPS-protein gel interactions depending on the incubation period (Beal et al., 1999; de Kruif and Tuinier, 2001; Hassan et al., 2003a; Ozdemir and Kilic, 2004). The type of strain used for inoculation significantly $(P$ $<0.05)$ affected the $\eta_{50}$ of ayran samples depending on the interaction of EPS production and culture-incubation temperature (Table 4). Generally, the $\eta_{50}$ of ayran samples produced with strain 2 was higher than those samples produced with strain 1 , whereas the lowest $\eta_{50}$ values were detected for ayran samples produced with the control strain, indicating the important role of EPS in ayran rheology. The mixture of 2 EPS-producing strains resulted in the highest $\eta_{50}$ values, indicating the relationship between EPS production levels and ayran viscosity (Table 4). In fact, these results were consistent with the in situ EPS production levels by these strains (Table 2), showing the crucial role of EPS production in rheological properties of ayran. Similarly, production of 2 different EPS can also explain the higher $\eta_{50}$ values in ayran samples produced with strain mixture, as previously reported (Faber et al., 1998). Our results were in contrast to previous observations in which ayran produced with nonropy cultures demonstrated higher $\eta_{50}$ values than those produced with ropy cultures, and EPS production, rather than differences in acidification properties of nonropy and ropy cultures, was stated to be the reason for the lower $\eta_{50}$ values in ayran produced with ropy cultures (Ozdemir and Kilic, 2004). The potential negative role of EPS in ayran or yogurt samples is thought to be associated with the potential prevention of protein-protein interactions by EPS during the fermentation process (Hassan et al., 1996; Marshall and Rawson, 1999; Ozdemir and Kilic, 2004). In contrast, EPS production increases the aggregation in the protein network and interaction between EPS and casein matrix in yogurt and therefore increases yogurt viscosity (Rawson and Marshall, 1997; Hassan et al., 2003a). On the other hand, it has been reported that 2 S. thermophilus strains produced significantly different amounts of EPS but the $\eta_{50}$ values of fermented milk products with these strains were found to be similar; this similarity was reported to be related to the difference in final EPS structures (De Vuyst et al., 2003). It should be noted here that LAB can produce a great variety of EPS differing in yield and structural and compositional characteristics, including net charge and molecular mass, which affect the rheological characteristics of EPS. The contrasting results reported are probably related to differences in these properties (Rawson and Marshall, 1997; Kleerebezem et al., 1999; Duboc and Mollet, 2001; Ruas-Madiedo et al., 2002a). Furthermore, carbohydrate-based stabilizers reportedly increase the apparent viscosity values of ayran, which supports our observations, and EPS produced in situ by the strains used in this study could be used as a stabilizer to enhance the rheological properties of ayran (Koksoy and Kilic, 2004).

The model parameters consistency coefficient $(K)$ and flow behavior index $(n)$ were found to be significantly 


\section{Control}
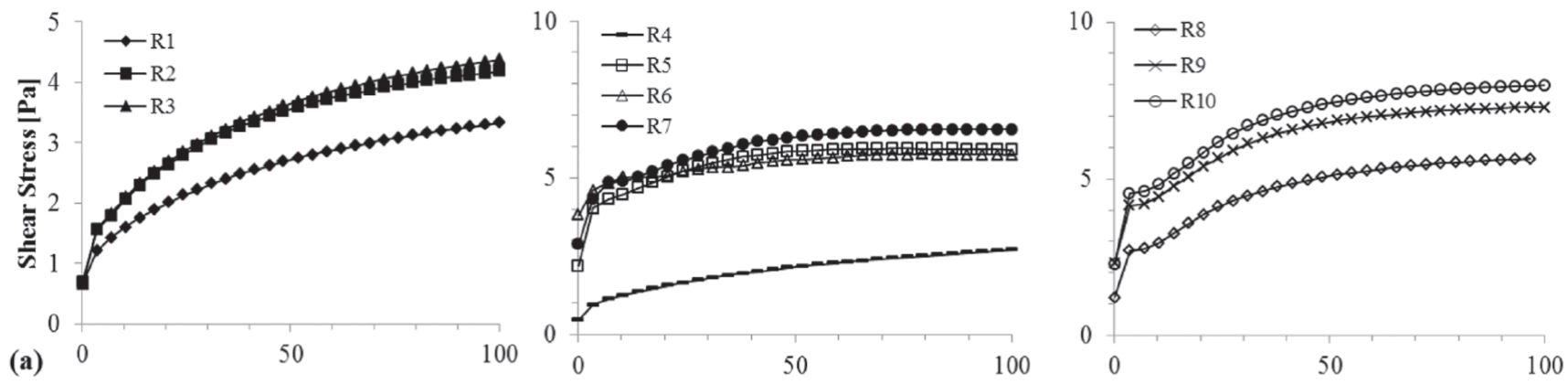

Strain 1
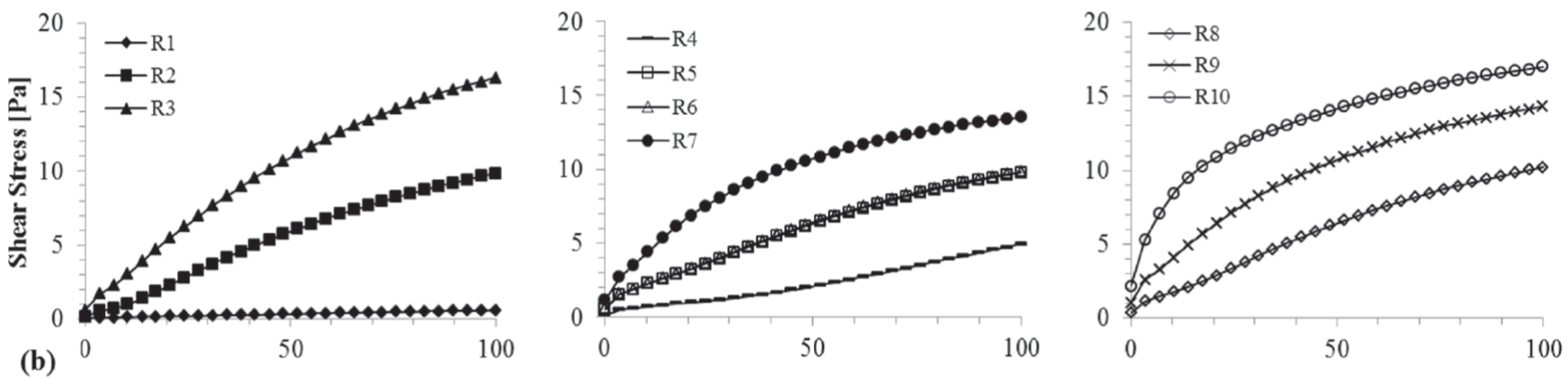

Strain 2
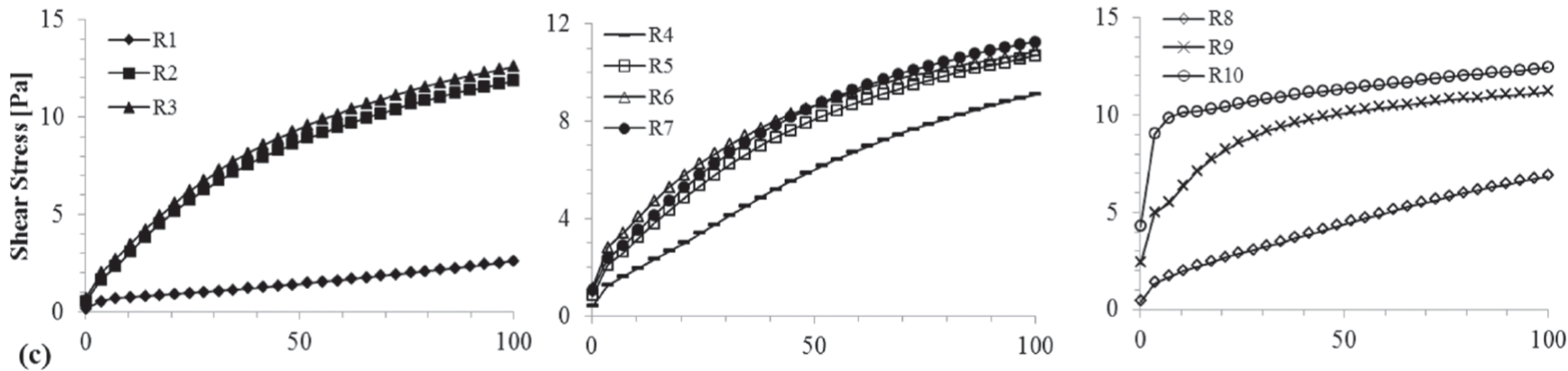

Mixture
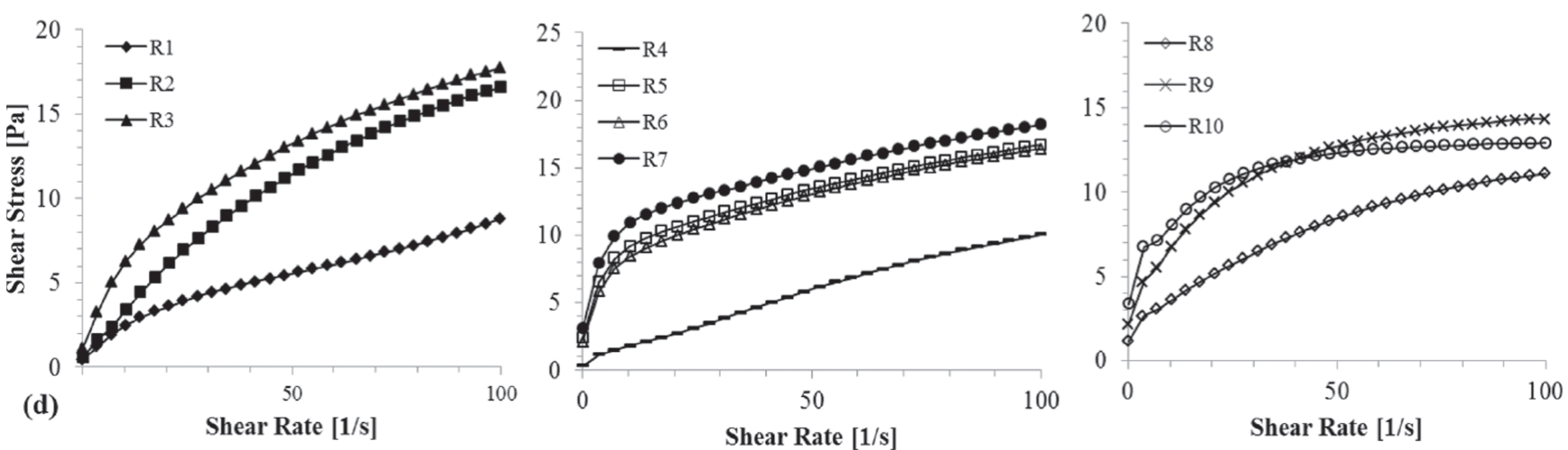

Figure 2. Shear stress versus shear rate data for ayran samples. Control = non-exopolysaccharide (EPS)-producing Streptococcus thermophilus strain; strains 1 and 2 = EPS-producing S. thermophilus strain; mixture = admixture of strains 1 and 2. 
$(P<0.05)$ altered depending on the strain-specific conditions and incubation temperature and time for ayran samples (Table 4 ). The $K$ values of ayran samples increased and $n$ values decreased with increasing incubation temperature and time, and the effect of incubation time was greater. For instance, the highest $K$ value $(8.384 \mathrm{~Pa} \cdot \mathrm{s})$ and the lowest $n$ value $(0.081)$ were determined for the sample incubated at $42^{\circ} \mathrm{C}$ for $4 \mathrm{~h}$ and produced with strain 2 (Table 4). Several studies have reported that higher incubation temperatures lead to increased $K$ values because of the formation of stronger gels compared with lower incubation temperatures in yogurt samples (Skriver et al., 1993; Haque et al., 2001; Shaker et al., 2002). Furthermore, a trend was reported for ayran that was in agreement with our observations (Ozdemir and Kilic, 2004) and, at higher temperatures, not only the alterations in protein network but also chemical and microbiological changes that might trigger alterations in protein network can explain the observed higher $K$ values. The effect of incubation time on $K$ values can be related to alterations in the protein network of ayran, as previously reported (Ozdemir and Kilic, 2004). It should be noted that water and ionic contents of ayran samples were found to be important for $K$ and $n$ values (Köksoy and Kılıç, 2003), but the effect of DM of ayran on these values was not clear in our study. The values of $K$ and $n$ were significantly affected by EPS production and generally the smallest changes in these values were detected for the control strain group. Furthermore, these values changed differently in other strain groups which in total suggest the enhancing role of EPS production in ayran rheology depending on EPS structure and production levels produced in situ during ayran fermentation (Table 4). Previous reports suggest that yogurt viscosity was strain dependent, in which the structure of EPS and its interactions with milk proteins and cultures are thought to be important in this process, which can also be the case in ayran (Rawson and Marshall, 1997; Faber et al., 2001; Folkenberg et al., 2006; Purwandari et al., 2007).

Steady shear rheology parameters of ayran samples in all groups were significantly affected by incubation temperature and time (Table 4). Therefore, these parameters were modeled to determine the effect of incubation temperature and time. Table 4 shows the $F$-values of model parameters generated for $K, n$, and $\eta_{50}$ values for ayran samples. To check the competence of the models, $\mathrm{R}^{2}$, adjusted $\mathrm{R}^{2}$, predicted $\mathrm{R}^{2}$, and adequate precision values were determined (Table 4). In these models, $\mathrm{R}^{2}$ values for $\eta_{50}$ were calculated to be $0.9558,0.9083,0.8899$, and 0.9731 for samples produced with strain 1 , strain 2 , control strain, and the mixture, respectively. Similarly, $\mathrm{R}^{2}$ values for $K$ and $n$ parameters ranged between 0.8012 and 0.9960 and between 0.7573 and 0.9910 , respectively, depending on the strain tested. All parameters used in the models were necessary to construct the correct model, as can be seen by the closeness of the $R^{2}$ and adjusted $R^{2}$ values to 1 . Similarly, the adequate precision values for each parameter, which reflects the signal to noise ratio, were in the desirable range (Toker et al., 2013).

The effects of incubation temperature and time on $K, n$, and $\eta_{50}$ of ayran samples are reported in Table 4. Results revealed that linear effects of both incubation temperature and time significantly $(P<0.01 ; P<0.05)$ affected the model parameters for all strain conditions in ayran samples. Similarly, as can be seen in Table 4, several trends were observed for the effect of interaction of factors (temperature $\times$ time) on model parameters for samples. In Figure 3, these effects are illustrated as 3 -dimensional response surfaces in which the direction of the effects of incubation temperature and time on these model parameters for all ayran strains can be seen. Furthermore, the second-order regression model equations predicting effects of incubation temperature and time are presented in Figure 3. These graphs show that the $K$ values of ayran samples produced with EPS-producing strains increased notably with incubation temperature and time, and several trends were observed for different strain conditions for these factors. For instance, the quadratic effect of temperature was the most determining factor for $K$ in the control group, showing a negative effect that indicates the presence of an optimum temperature for this value in the control sample. In contrast, the linear effect of incubation time was the most determining factor for $K$ in samples produced with strains 1 and 2 and the mixture, respectively, and positively affected this value. Consistent with the observations in $K$ values, $n$ values of all samples decreased notably with incubation temperature and time (Figure 3). The effect of incubation time was the most important factor to explain the $n$ values of ayran samples produced with control strain and strain 1 , whereas incubation temperature had a more important effect on $n$ value of samples produced with the mixture of strains. Both incubation temperature and time similarly affected the $n$ value of ayran produced with strain 2 . As can be seen in Figure $3, \eta_{50}$ values of all ayran samples increased with incubation temperature and time. Incubation temperature was the most effective factor in apparent viscosity of ayran samples produced with control strain and strain 1, respectively, whereas incubation time was the most effective variable for the apparent viscosity of samples produced with strain 2 and the mixture of strains, respectively (Figure 3 ). This value was negatively affected when these 2 factors interacted in ayran manufactured with strain 1 and with the quadratic effect of incubation period in 


\section{Control}
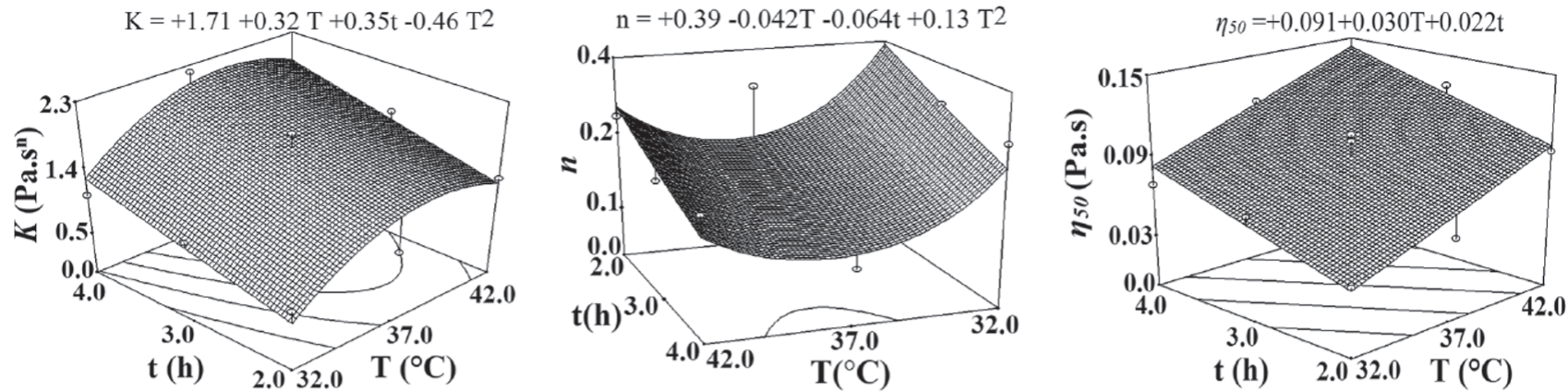

\section{Strain 1}
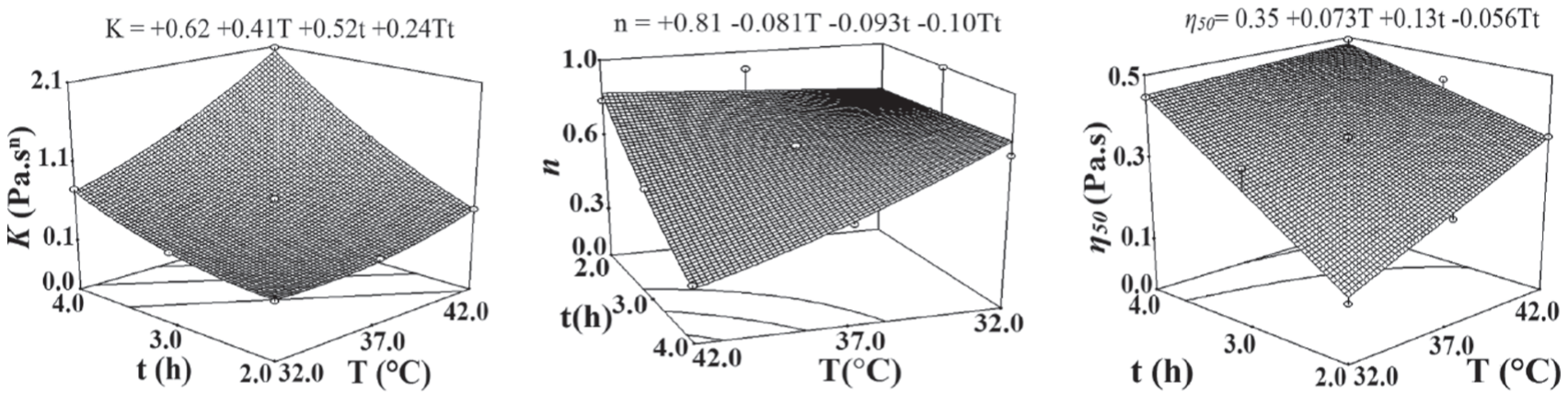

\section{Strain 2}
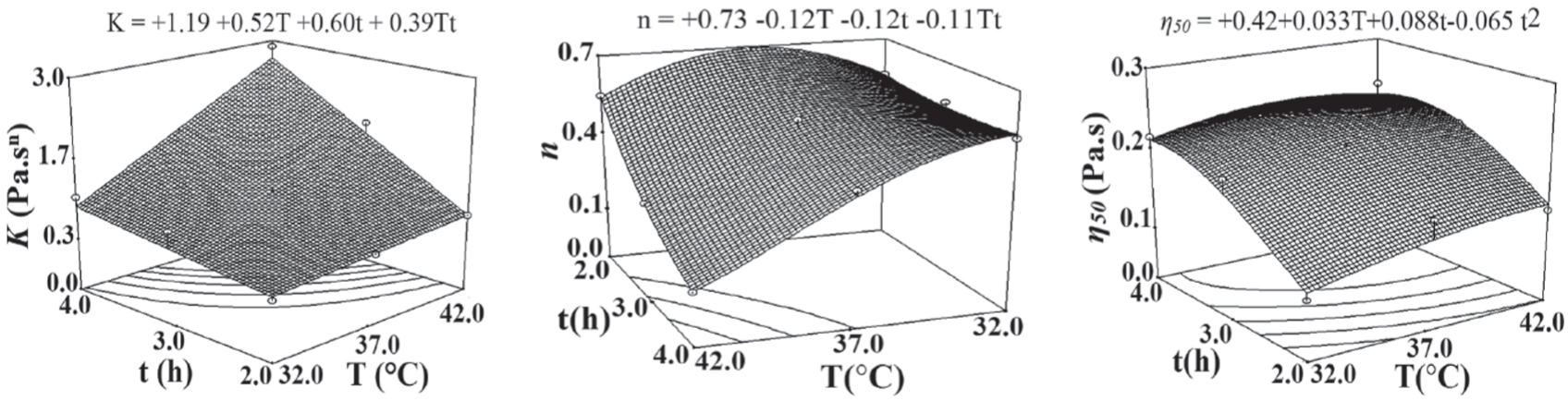

\section{Mixture}
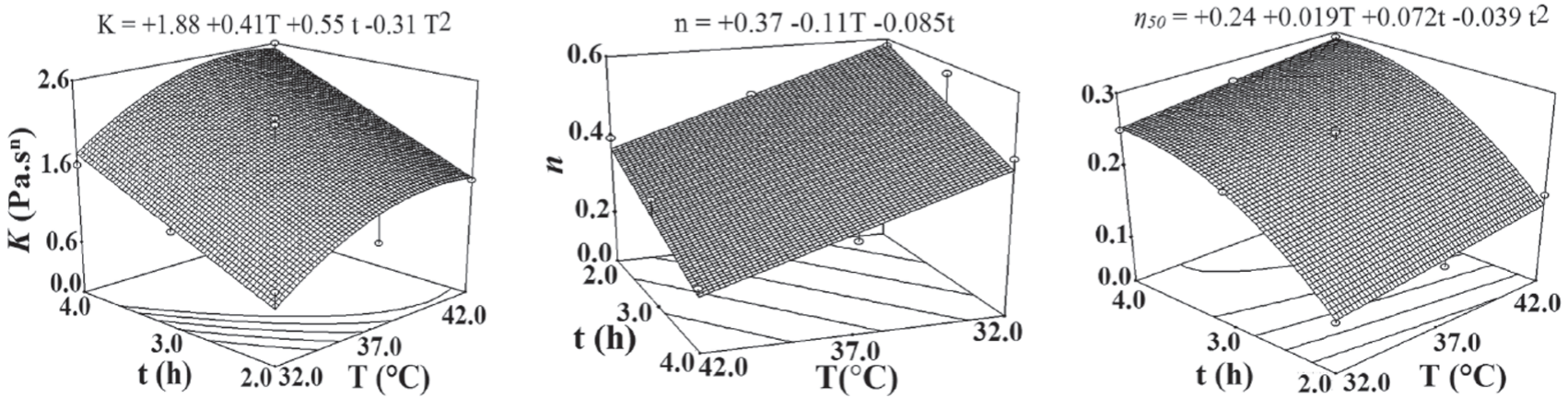

Figure 3. Effect of temperature $(\mathrm{T})$ and time (t) on $K$ (consistency coefficient), $\eta_{50}$ (apparent viscosity), and $n$ (flow behavior index) values of ayran samples. Control = non-exopolysaccharide (EPS)-producing Streptococcus thermophilus strain; strains 1 and $2=$ EPS-producing $S$. thermophilus strain; mixture $=$ admixture of strains 1 and 2 . 
ayran produced with strain 2 and the mixture of strains (Figure 3).

To calculate the optimum incubation temperature and time on rheological parameters of ayran and EPS production levels and to determine the EPS yields resulting in maximum and minimum $K, n$, and $\eta_{50}$ values, single-response (SRO) and multiple-response (MRO) optimization analyses were applied and the results are presented in Table 5. As can be seen from the SRO analysis, EPS yield was minimal at $32^{\circ} \mathrm{C}$ for $2.1 \mathrm{~h}$ incubation and final EPS yield was found to be maximal when the fermentation was conducted at $37.4^{\circ} \mathrm{C}$ for 3.9 $\mathrm{h}$ (Table 5). Additionally, the incubation parameters that resulted in minimum and maximum $K, n$, and $\eta_{50}$ values were $32.1^{\circ} \mathrm{C}$ for $0.2 \mathrm{~h}, 41.1^{\circ} \mathrm{C}$ for $4 \mathrm{~h}$, and $32^{\circ} \mathrm{C}$ for $2 \mathrm{~h}$ (minimum values) and $42^{\circ} \mathrm{C}$ for $4 \mathrm{~h}, 32^{\circ} \mathrm{C}$ for 2 $\mathrm{h}$, and $42^{\circ} \mathrm{C}$ for $3.9 \mathrm{~h}$ (maximum values), respectively. Several trends were observed for optimal factor levels for SRO for EPS yield and rheological parameters and are given in Table 5. The optimal conditions for the rheological parameters that resulted in minimum and maximum EPS yields for different strain conditions were determined by using MRO analysis (Table 5 ). For instance, the minimum $K$ value was recorded at $32.1^{\circ} \mathrm{C}$ for $0.2 \mathrm{~h}$ for the strain mixture; at the same temperature but with an increase of incubation time to $2.1 \mathrm{~h}$, EPS yield was minimal for the strain mixture, and, at this condition, the value of $K$ was nearly doubled, showing the crucial role of incubation temperature and EPS production on this parameter (Table 5). A similar trend was observed for the maximum EPS yield incubation conditions affecting the $K$ value, showing the crucial role of both EPS yield and incubation conditions on physicochemical properties of ayran. In contrast to the strain mixture, the minimal EPS yields for strains 1 and 2 were obtained at $41.8^{\circ} \mathrm{C}$ for $2.7 \mathrm{~h}$ and $41.9^{\circ} \mathrm{C}$ for $2 \mathrm{~h}$ incubation, respectively, after SRO analysis but similar trends were observed for the rheological parameters except the $n$ value for strain 1 , showing the crucial role of incubation temperature and time on rheological parameters (Table 5). Addition of MRO analysis confirmed this role because at maximum EPS yield at $32^{\circ} \mathrm{C}$ for strain 1 , the $K$ value was $0.1 \mathrm{~Pa} \cdot \mathrm{s}^{n}$ and at minimum EPS yield at $41.8^{\circ} \mathrm{C}$, this value was $0.7 \mathrm{~Pa} \cdot \mathrm{s}^{n}$, which can be related to the stronger protein network at $41.8^{\circ} \mathrm{C}$ that resulted in higher $K$ values. Table 6 gives Pearson correlation coefficients between rheological parameters and EPS yield for different strain conditions. At all strain conditions, a significant positive correlation was found between $K$ and $\eta_{50}$, as expected (Table 6 ). Interestingly, no significant positive correlation was observed between EPS yield and $K$ value for strains 1 and 2, which can be can be explained by different gelling conditions. For the strain mixture, however, this
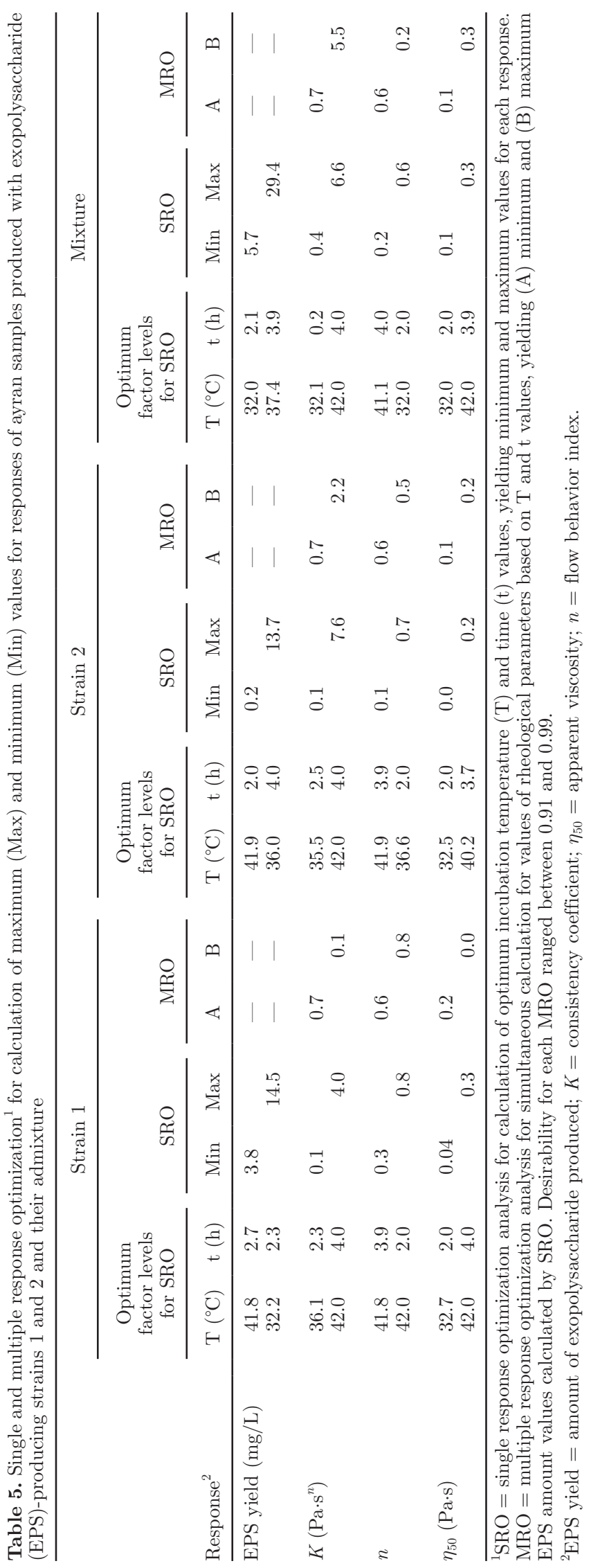
Table 6. Pearson correlation coefficients (r) between rheological parameters and amounts of exopolysaccharide (EPS) produced by different strains $^{1}$

\begin{tabular}{|c|c|c|c|c|c|c|c|c|c|c|c|c|}
\hline \multirow[b]{2}{*}{ Parameter $^{1}$} & \multicolumn{12}{|c|}{ Ayran samples inoculated with different strains ${ }^{2}$} \\
\hline & $K$ & $\eta_{50}$ & EPS & $K$ & $\eta_{50}$ & EPS & $K$ & $\eta_{50}$ & EPS & $K$ & $\eta_{50}$ & EPS \\
\hline $\bar{K}$ & 1.000 & & & 1.000 & & & 1.000 & & & 1.000 & & \\
\hline$\eta_{50}$ & $0.817^{*}$ & 1.000 & & $0.749^{*}$ & 1.000 & & $0.598^{*}$ & 1.000 & & $0.855^{* *}$ & 1.000 & \\
\hline EPS & $\begin{array}{r}0.011 \\
-3\end{array}$ & 1.00 & 1.000 & -0.384 & -0.481 & 1.000 & 0.201 & $0.733^{*}$ & 1.000 & $0.780^{* *}$ & $0.628^{*}$ & 1.000 \\
\hline
\end{tabular}

${ }^{1} K=$ consistency coefficient, $\eta_{50}=$ apparent viscosity at $50 \mathrm{~s}^{-1}$, EPS $=$ amount of EPS produced by different strains. $K, \eta_{50}$, and EPS amount values were used to perform the Pearson correlation analysis $\left(* P<0.05,{ }^{*} P<0.01\right)$.

${ }^{2}$ Control = non-EPS-producing Streptococcus thermophilus strain; strains 1 and $2=$ EPS-producing S. thermophilus strain; mixture = admixture of strains 1 and 2 .

${ }^{3}$ Correlation analysis was not performed because control Ayran samples produced no EPS.

correlation was positive. Similarly, a positive correlation between $\eta_{50}$ and EPS yield was noted for all strain conditions except strain 1 (Table 6). Exopolysaccharide is the focus of much recent interest in the food industry and optimization studies should be applied to determine the complex interactions between EPS yield and fermentation kinetics. For such a product such as ayran, in which the use of gelling agents is not permitted, these studies are important.

Figures 4 and 5 show representative scanning electron micrographs of the ayran samples produced with different strains, which allowed analysis of the interactions of EPS with ayran components, especially proteins, and observation of the bacterial cells within the ayran microstructure. As can be seen in Figure 4A, B, and C, the ayran produced with the non-EPS-producing control strain had a compact appearance under different incubation conditions, consistent with that reported for other milk products (Hassan et al., 2003b); this compact structure is related to the aggregation of proteins caused by the heat treatment process during buttermilk production (Ayala-Hernandez et al., 2008). In contrast, Figure 4D, E, and F and Figure 5 show the EPS filaments attached to the bacteria and the protein network in ayran samples produced with EPS-producing strains under different incubation conditions. Large pores can be observed in the ayran samples that have a web-like structure due to the EPS network within proteins (Hassan et al., 2003a,b). Attachment of bacterial cells to the protein network via EPS filaments can be seen in the scanning electron micrographs. These images reveal the importance of in situ EPS production during ayran production and support the crucial role of EPS production for the rheological and technological properties of ayran, as reported for other dairy products (Hassan et al., 2003b; Ayala-Hernandez et al., 2008).

One of the important aspects of food products is their sensory properties. In this respect, we evaluated the sensory properties of ayran samples produced with different EPS-producing strains and under different incubation conditions (Table 7). In general, different EPS-producing strains and incubation conditions did not greatly affect the color of ayran samples, although several trends were observed (Table 7). The sample with the lowest score for color was that produced with the $\mathrm{EPS}^{-}$strain and incubated at $32^{\circ} \mathrm{C}$ for $4 \mathrm{~h}$. In contrast, the color scores of the rest of the ayran samples were similar (Table 7). The samples produced with strain 1 had the highest score for appearance under all incubation conditions tested. However, when the strain mixture was used, the overall appearance score decreased slightly. The samples with the mixture of strains and incubated at $32^{\circ} \mathrm{C}$ for $2 \mathrm{~h}$ had the lowest appearance score, but under other incubation conditions, the appearance score was similar to the other strains tested. We observed a trend for a slight decrease in the appearance scores of ayran samples produced with the EPS $^{-}$strain (Table 7 ). These results suggest that in situ EPS production enhances the color and appearance properties of ayran without any adverse effect depending on the incubation conditions. Previously it was reported that use of alginate and pectin resulted in the lowest appearance and color scores for yogurt samples compared with control samples (Kumar and Mishra, 2004). Similarly, it was found that the appearance scores and the overall acceptability of yogurt decreased when gums were used at a concentration $>0.28 \%$ (Teles and Flôres, 2007). Odor is an important sensory criterion for dairy products, in which certain chemical compounds formed during the fermentation process play important roles. The odor scores of ayran samples produced with strain 1 or strain 2 increased with increasing incubation temperature and time, but when these strains were combined, similar odor scores were observed for all incubation conditions tested, and these values were similar to the odor scores determined 

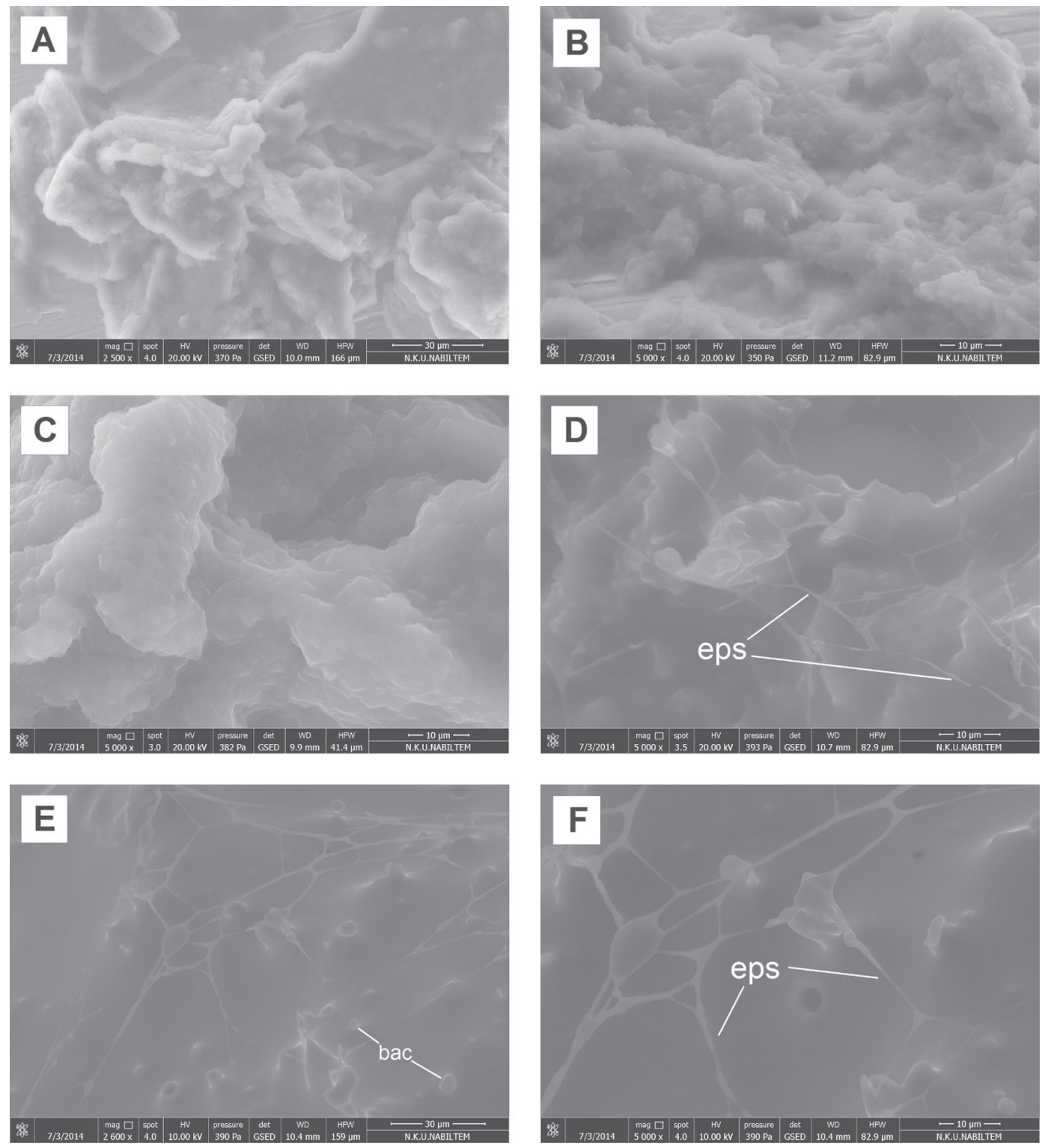

Figure 4. Scanning electron micrographs of ayran samples. A, B, C = control [non-exopolysaccharide (EPS)-producing Streptococcus thermophilus strain] samples in runs 1, 5, and 10, respectively; D, E, F = samples inoculated with strain 1 (EPS-producing Streptococcus thermophilus strain) in runs 1, 5, and 10, respectively; bac = exopolysaccharide (EPS)-producing bacteria; eps = network strands indicating EPS structure. Table 1 describes the experimental runs.

for the control group ayran samples (Table 7). The use of hydrocolloids negatively affects the odor properties of ayran (Koksoy and Kilic, 2004) but no negative effect was observed in our study with the in situ EPS production. We also evaluated the taste properties of ayran samples produced under different incubation conditions, and the taste of ayran was the most variable sensory property among strains and conditions tested (Table 7). In general, increasing the incubation temperature and time resulted in higher scores when strain 1 or strain 2 was used, but scores fluctuated in ayran produced with control strain and the mixture of the 2 strains depending on the conditions tested. No clear adverse effect of EPS on taste properties of ayran was detected. This finding is in contrast to previous results in which flavor properties of yogurt samples produced with non-EPS-producing strains were reported to be higher, which was attributed to the higher acetaldehyde content, not as a direct negative role of EPS production (Guzel-Seydim et al., 2005; Güler-Akin et al., 2009). It is expected that EPS would not negatively affect taste of ayran because EPS have no taste (Duboc and Mollet, 2001). However, as with odor properties, addition of stabilizers to ayran results in a decline in its taste 

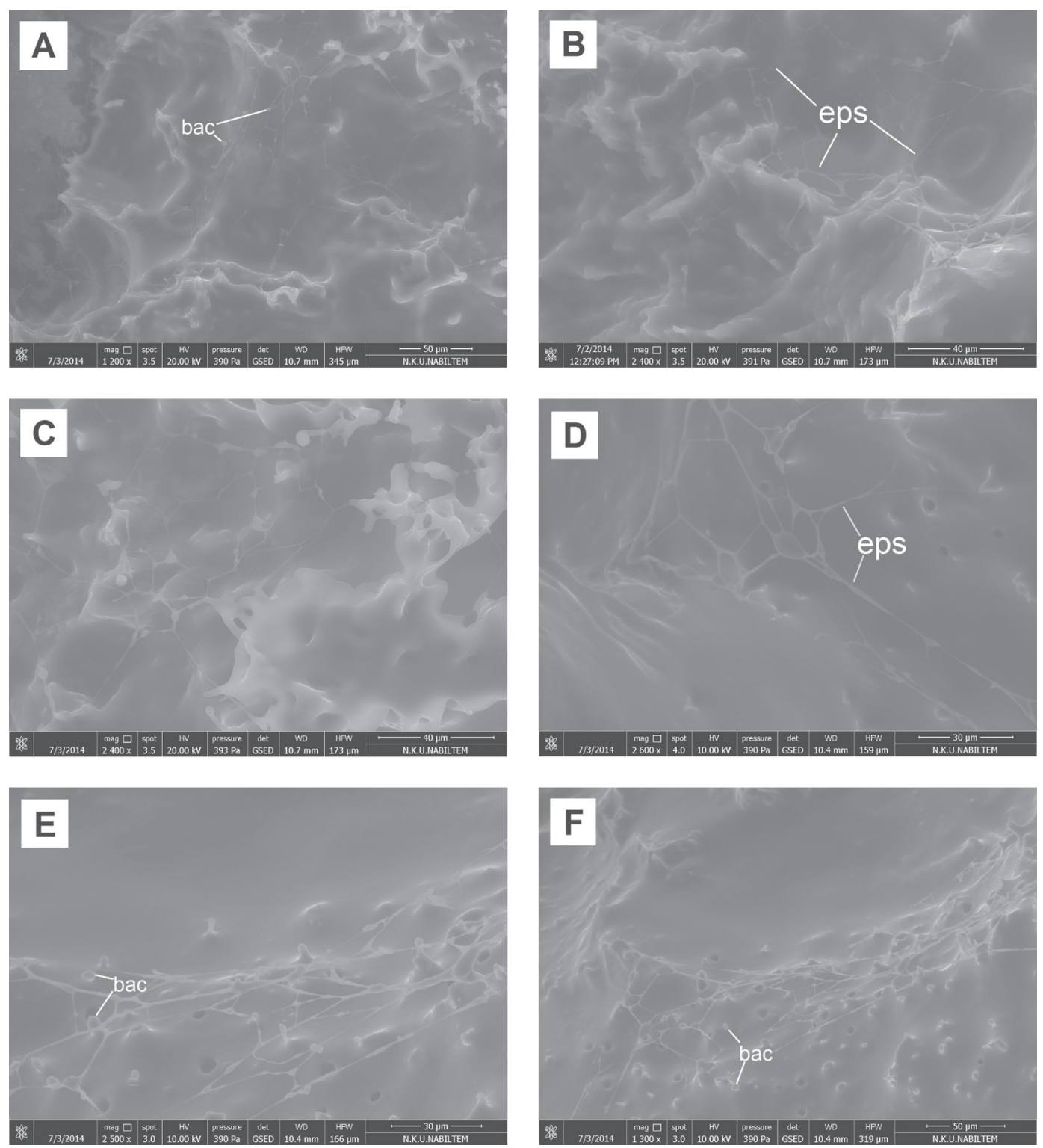

Figure 5. Scanning electron micrographs of ayran samples. A, B, C = samples inoculated with strain 2 [exopolysaccharide (EPS)-producing Streptococcus thermophilus strain] in runs 1, 5, and 10, respectively; D, E, F = samples inoculated with an admixture of strain 1 and strain 2 [both EPS-producing Streptococcus thermophilus strains] in runs 1, 5, and 10, respectively; bac = EPS-producing bacteria; eps = network strands indicating EPS structure. Table 1 describes the experimental runs.

perception (Koksoy and Kilic, 2004), which was not recorded in our study. Inoculation and incubation conditions also affected viscosity scores for ayran samples (Table 7). Generally, viscosity scores did not vary much between EPS-producing strains and the control strain, in contrast to the physical viscosity measurements, and the lowest viscosity score was recorded in the control ayran group. Furthermore, the significant physical viscosity alterations depending on incubation temperature and time were not fully reflected in the sensory scores. This difference is thought to be related to the viscosity perception of panelists as a result of sensory character- istics such as mouth feel, appearance, and processing (Teles and Flôres, 2007). Similar observations were reported for the use of stabilizers in which the physical viscosity of ayran samples significantly increased, but this increase was not reflected in the sensory evaluation (Koksoy and Kilic, 2004). Previously, it was reported that use of EPS-producing cultures enhances viscosity and mouthfeel perceptions and thus, EPS could be used as a fat replacer without any detrimental effect on the overall acceptance of yogurt samples (Güler-Akin et al., 2009). General acceptance scores of ayran samples were altered in a similar manner to viscosity scores (Table 
Table 7. Sensory properties of ayran samples inoculated with different strains ${ }^{1}$

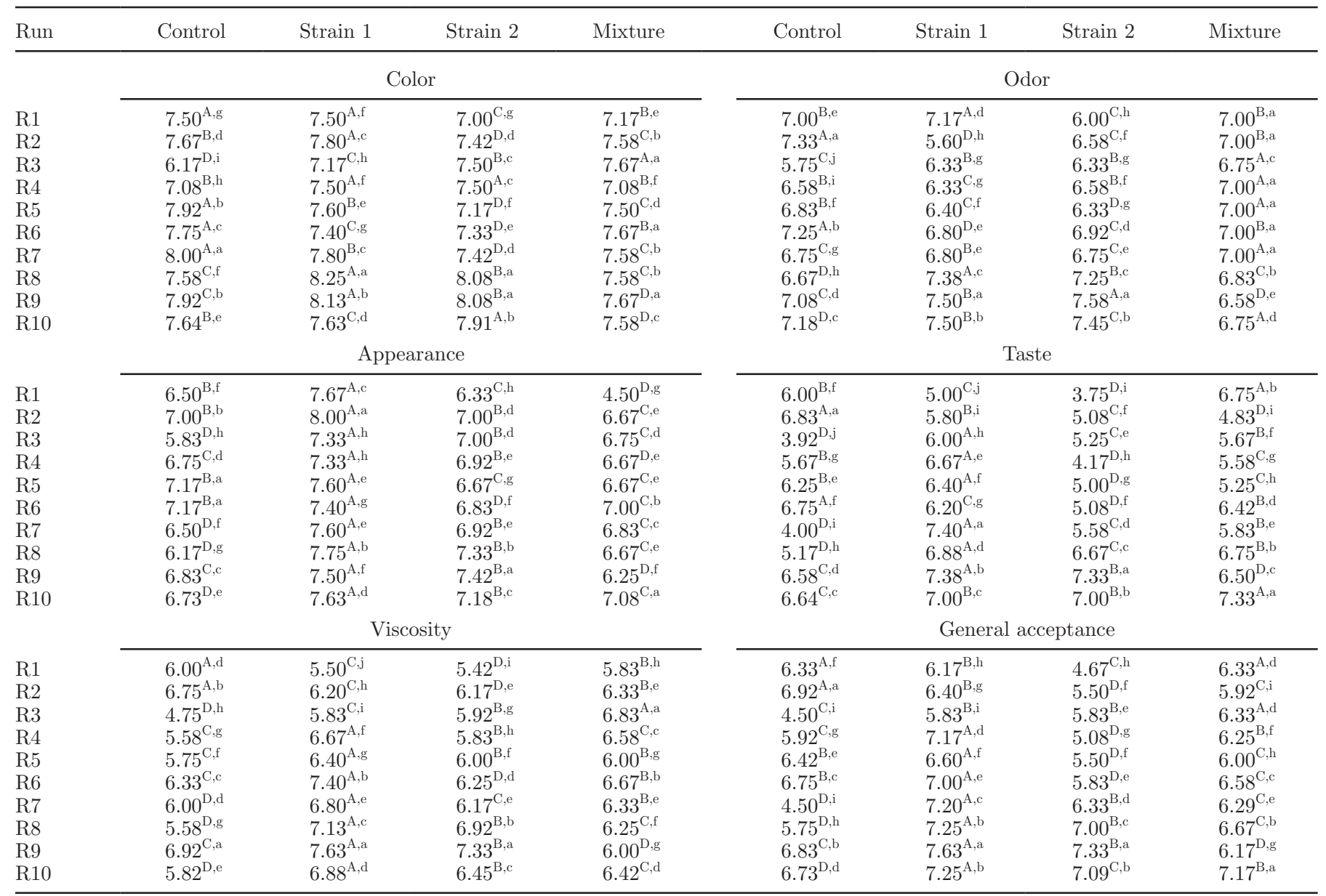

$\overline{\mathrm{A}-\mathrm{D}}$ Different uppercase superscript letters show differences between strains within the same run $(P<0.05)$.

${ }^{\mathrm{a}-\mathrm{j} D i f f e r e n t ~ l o w e r c a s e ~ s u p e r s c r i p t ~ l e t t e r s ~ s h o w ~ d i f f e r e n c e s ~ b e t w e e n ~ r u n s ~ w i t h i n ~ t h e ~ s a m e ~ s t r a i n ~}(P<0.05)$.

${ }^{1}$ Control = non-EPS-producing Streptococcus thermophilus strain; strains 1 and $2=$ EPS-producing $S$. thermophilus strain; mixture $=$ admixture of strains 1 and 2 .

7). The highest scores were obtained for ayran samples produced with the mixture of strains; when EPS-producing strains were used individually, we observed a linear correlation between incubation temperature and time and general acceptance scores of ayran samples. Furthermore, no direct adverse effect of in situ EPS production was recorded for the general acceptance of ayran samples, in contrast to when hydrocolloids are used in ayran production (Koksoy and Kilic, 2004). Overall, the sensory characteristics of ayran were significantly affected by the incubation conditions, and the type of starter culture, in which EPS production was determinant, was significant in these properties.

\section{CONCLUSIONS}

In this study, we studied the effects of incubation conditions and selection of starter culture based on in situ EPS production on rheological and technological properties of ayran samples. In addition, we modeled the role of fermentation conditions and EPS production on ayran rheology and optimized the factors affecting EPS production using response surface methodology. The chemical and microbiological characteristics of ayran were altered by the incubation conditions. Both incubation temperature and time significantly affected the rheological properties of ayran, the latter having a greater effect on ayran rheology. In situ EPS production led to a significant increase in viscosity, which indicates a correlation between EPS production and rheological properties of fermented milk products. Both incubation temperature and time affected in situ EPS yield during production but the most important factor in EPS yield was strain-specific metabolism. We conclude that the determination of rheological and technological properties of fermented milk products such as ayran is enor- 
mously complex. One of the factors in this complexity is the variability in EPS yield and EPS structure, which determine the interactions of EPS with the protein network in fermented milk products. In this respect, more studies are required to identify EPS yield of different LAB strains under different fermentation conditions in order to optimize fermentation kinetics. However, selection of EPS-producing starter cultures to add viscosity and texture is a promising tool that can add significant value to the technological and organoleptic properties of fermented products.

\section{ACKNOWLEDGMENTS}

This work was supported by The Scientific and Technological Research Council of Turkey (TOVAG, Ankara, Turkey; project no. 112O169). The authors declare that they have no conflict of interest.

\section{REFERENCES}

Akın, S., and G. Siddık. 1999. Effect of viscous cultures on the rheological and sensory properties, flavor substances and starter bacteria counts of set yogurt. Gida (Food) 24:319-325.

Altay, F., F. Karbancioglu-Guler, C. Daskaya-Dikmen, and D. Heperkan. 2013. A review on traditional Turkish fermented non-alcoholic beverages: Microbiota, fermentation process and quality characteristics. Int. J. Food Microbiol. 167:44-56.

Ayala-Hernandez, I., H. D. Goff, and M. Corredig. 2008. Interactions between milk proteins and exopolysaccharides produced by Lactococcus lactis observed by scanning electron microscopy. J. Dairy Sci. 91:2583-2590.

Beal, C., J. Skokanova, E. Latrille, N. Martin, and G. Corrieu. 1999. Combined effects of culture conditions and storage time on acidification and viscosity of stirred yogurt. J. Dairy Sci. 82:673-681.

Broadbent, J. R., D. J. McMahon, D. L. Welker, C. J. Oberg, and S. Moineau. 2003. Biochemistry, genetics, and applications of exopolysaccharide production in Streptococcus thermophilus: A review. J. Dairy Sci. 86:407-423.

de Kruif, C. G., and R. Tuinier. 2001. Polysaccharide protein interactions. Food Hydrocoll. 15:555-563.

De Vuyst, L., and B. Degeest. 1999. Heteropolysaccharides from lactic acid bacteria. FEMS Microbiol. Rev. 23:153-177.

De Vuyst, L., F. Vanderveken, S. Van de Ven, and B. Degeest. 1998 Production by and isolation of exopolysaccharides from Streptococcus thermophilus grown in a milk medium and evidence for their growth-associated biosynthesis. J. Appl. Microbiol. 84:1059-1068.

De Vuyst, L., M. Zamfir, F. Mozzi, T. Adriany, V. Marshall, B. Degeest, and F. Vaningelgem. 2003. Exopolysaccharide-producing Streptococcus thermophilus strains as functional starter cultures in the production of fermented milks. Int. Dairy J. 13:707-717.

Derringer, G., and R. Suich. 1980. Simultaneous optimization of several response variables. J. Qual. Technol. 12:214-219.

Dertli, E., I. J. Colquhoun, A. P. Gunning, R. J. Bongaerts, G. Le Gall, B. B. Bonev, M. J. Mayer, and A. Narbad. 2013. Structure and biosynthesis of two exopolysaccharides produced by Lactobacillus johnsonii FI9785. J. Biol. Chem. 288:31938-31951.

Duboc, P., and B. Mollet. 2001. Applications of exopolysaccharides in the dairy industry. Int. Dairy J. 11:759-768.

DuBois, M., K. A. Gilles, J. K. Hamilton, P. A. Rebers, and F. Smith. 1956. Colorimetric method for determination of sugars and related substances. Anal. Chem. 28:350-356.

Erkaya, T., M. Başlar, M. Şengül, and M. F. Ertugay. 2014. Effect of thermosonication on physicochemical, microbiological and senso- rial characteristics of ayran during storage. Ultrason. Sonochem. http://dx.doi.org/10.1016/j.ultsonch.2014.08.009.

Faber, E. J., M. J. van den Haak, J. P. Kamerling, and J. F. Vliegenthart. 2001. Structure of the exopolysaccharide produced by Streptococcus thermophilus S3. Carbohydr. Res. 331:173-182.

Faber, E. J., P. Zoon, J. P. Kamerling, and J. F. G. Vliegenthart. 1998. The exopolysaccharides produced by Streptococcus thermophilus RS and STS have the same repeating unit but differ in viscosity of their milk cultures. Carbohydr. Res. 310:269-276.

Folkenberg, D. M., P. Dejmek, A. Skriver, and R. Ipsen. 2005. Relation between sensory texture properties and exopolysaccharide distribution in set and in stirred yoghurts produced with different starter cultures. J. Texture Stud. 36:174-189.

Folkenberg, D. M., P. Dejmek, A. Skriver, H. Skov Guldager, and R. Ipsen. 2006. Sensory and rheological screening of exopolysaccharide producing strains of bacterial yoghurt cultures. Int. Dairy J. 16:111-118.

Grobben, G. J., W. H. M. van Casteren, H. A. Schols, A. Oosterveld, G. Sala, M. R. Smith, J. Sikkema, and J. A. M. de Bont. 1997. Analysis of the exopolysaccharides produced by Lactobacillus delbrueckii ssp. bulgaricus NCFB 2772 grown in continuous culture on glucose and fructose. Appl. Microbiol. Biotechnol. 48:516-521.

Güler-Akin, M. B., M. Serdar Akin, and A. Korkmaz. 2009. Influence of different exopolysaccharide-producing strains on the physicochemical, sensory and syneresis characteristics of reduced-fat stirred yoghurt. Int. J. Dairy Technol. 62:422-430.

Gülmez, M., A. Güven, C. Sezer, and B. Duman. 2003. Evaluation of microbiological and chemical quality of ayran samples marketed in Kars and Ankara cities in Turkey. Kafkas Univ. Vet. Fak. Derg. 9:49-52.

Guzel-Seydim, Z. B., E. Sezgin, and A. C. Seydim. 2005. Influences of exopolysaccharide producing cultures on the quality of plain set type yogurt. Food Contr. 16:205-209.

Haque, A., R. K. Richardson, and E. R. Morris. 2001. Effect of fermentation temperature on the rheology of set and stirred yogurt. Food Hydrocoll. 15:593-602.

Hassan, A. N., J. F. Frank, and M. Elsoda. 2003b. Observation of bacterial exopolysaccharide in dairy products using cryo-scanning electron microscopy. Int. Dairy J. 13:755-762.

Hassan, A. N., J. F. Frank, K. A. Schmidt, and S. I. Shalabi. 1996. Rheological properties of yogurt made with encapsulated nonropy lactic cultures. J. Dairy Sci. 79:2091-2097.

Hassan, A. N., R. Ipsen, T. Janzen, and K. B. Qvist. 2003a. Microstructure and rheology of yogurt made with cultures differing only in their ability to produce exopolysaccharides. J. Dairy Sci. 86:1632-1638.

Hejazi, T. H., M. Bashiri, J. Diaz-Garcia, and K. Noghondarian. 2012. Optimization of probabilistic multiple response surfaces. Appl. Math. Model. 36:1275-1285.

Kimmel, S. A., R. F. Roberts, and G. R. Ziegler. 1998. Optimization of exopolysaccharide production by Lactobacillus delbrueckii ssp. bulgaricus RR grown in a semidefined medium. Appl. Environ. Microbiol. 64:659-664.

Kleerebezem, M., R. van Kranenburg, R. Tuinier, I. C. Boels, P. Zoon, E. Looijesteijn, J. Hugenholtz, and W. M. de Vos. 1999. Exopolysaccharides produced by Lactococcus lactis: From genetic engineering to improved rheological properties. Antonie van Leeuwenhoek $76: 357-365$.

Kojic, M., M. Vujcic, A. Banina, P. Cocconcelli, J. Cerning, and L. Topisirovic. 1992. Analysis of exopolysaccharide production by Lactobacillus casei CG11, isolated from cheese. Appl. Environ. Microbiol. 58:4086-4088.

Köksoy, A., and M. Kılıç. 2003. Effects of water and salt level on rheological properties of Ayran, a Turkish yoghurt drink. Int. Dairy J. $13: 835-839$.

Koksoy, A., and M. Kilic. 2004. Use of hydrocolloids in textural stabilization of a yoghurt drink, ayran. Food Hydrocoll. 18:593-600.

Kumar, P., and H. N. Mishra. 2004. Mango soy fortified set yoghurt: effect of stabilizer addition on physicochemical, sensory and textural properties. Food Chem. 87:501-507. 
Marshall, V. M., and H. L. Rawson. 1999. Effects of exopolysaccharide-producing strains of thermophilic lactic acid bacteria on the texture of stirred yoghurt. Int. J. Food Sci. Technol. 34:137-143.

Metin, M. 2008. Sut ve Mamulleri Analiz Yontemleri. Ege Üniversitesi Bornova-İzmir, Turkey.

Myers, R. H., and D. C. Montgomery. 1995. Response Surface Methodology. Process and Product Optimization Using Designed Experiments. Wiley, New York, NY.

Ozdemir, U., and M. Kilic. 2004. Influence of fermentation conditions on rheological properties and serum separation of Ayran. J. Texture Stud. 35:415-428.

Petry, S., S. Furlan, M. J. Crepeau, J. Cerning, and M. Desmazeaud. 2000. Factors affecting exocellular polysaccharide production by Lactobacillus delbrueckii ssp. bulgaricus grown in a chemically defined medium. Appl. Environ. Microbiol. 66:3427-3431.

Purwandari, U., N. P. Shah, and T. Vasiljevic. 2007. Effects of exopolysaccharide-producing strains of Streptococcus thermophilus on technological and rheological properties of set-type yoghurt. Int. Dairy J. 17:1344-1352.

Rawson, H. L., and V. M. Marshall. 1997. Effect of 'ropy' strains of Lactobacillus delbrueckii ssp. bulgaricus and Streptococcus thermophilus on rheology of stirred yogurt. Int. J. Food Sci. Technol. 32:213-220.

Ruas-Madiedo, P., J. Hugenholtz, and P. Zoon. 2002a. An overview of the functionality of exopolysaccharides produced by lactic acid bacteria. Int. Dairy J. 12:163-171.

Ruas-Madiedo, P., R. Tuinier, M. Kanning, and P. Zoon. 2002b. Role of exopolysaccharides produced by Lactococcus lactis ssp. cremoris on the viscosity of fermented milks. Int. Dairy J. 12:689-695.

Sanli, T., E. Sezgin, E. Senel, and M. Benli. 2011. Effects of using transglutaminase on properties of ayran in traditional production of Ayran. Gida (Food) 36:217-224.

Shaker, R. R., B. Abu-Jdayil, R. Y. Jumah, and S. A. Ibrahim. 2002. Rheological properties of set yogurt as influenced by incubation temperature and homogenization. J. Food Qual. 25:409-418.

Skriver, A., H. Roemer, and K. B. Qvist. 1993. Rheological characterization of stirred yoghurt: viscometry. J. Texture Stud. 24:185198
Sutherland, I. W. 1972. Bacterial exopolysaccharides. Adv. Microb. Physiol. 8:143-213.

Tallon, R., P. Bressollier, and M. C. Urdaci. 2003. Isolation and characterization of two exopolysaccharides produced by Lactobacillus plantarum EP56. Res. Microbiol. 154:705-712.

Tamucay-Özünlü, B., and C. Kocak. 2010a. The effect of different heat treatments of milk on quality of Ayran. Gida (Food) 35:355-362.

Tamucay-Özünlü, B., and C. Kocak. 2010b. Effect of ending the incubation at different pHs on quality of Ayran. Gida (Food) 35:113-119.

Teles, C. D., and S. H. Flôres. 2007. The influence of additives on the rheological and sensory properties of nonfat yogurt. Int. J. Dairy Technol. 60:270-276.

Toker, O. S., M. Dogan, N. B. Ersöz, and M. T. Yilmaz. 2013. Optimization of the content of 5-hydroxymethylfurfural (HMF) formed in some molasses types: HPLC-DAD analysis to determine effect of different storage time and temperature levels. Ind. Crops Prod. 50:137-144.

van den Berg, D., G. W. Robijn, A. C. Janssen, M. Giuseppin, R. Vreeker, J. P. Kamerling, J. Vliegenthart, A. M. Ledeboer, and C. T. Verrips. 1995. Production of a novel extracellular polysaccharide by Lactobacillus sake $0-1$ and characterization of the polysaccharide. Appl. Environ. Microbiol. 61:2840-2844.

Vaningelgem, F., M. Zamfir, F. Mozzi, T. Adriany, M. Vancanneyt, J. Swings, and L. De Vuyst. 2004. Biodiversity of exopolysaccharides produced by Streptococcus thermophilus strains is reflected in their production and their molecular and functional characteristics. Appl. Environ. Microbiol. 70:900-912.

Whitfield, C. 1988. Bacterial extracellular polysaccharides. Can. J. Microbiol. 34:415-420.

Yildiz, F. 2009. Development and Manufacture of Yogurt and Other Functional Dairy Products. CRC Press, Boca Raton, FL.

Yilmaz, M. T., S. Karaman, H. Cankurt, A. Kayacier, and O. Sagdic. 2011. Steady and dynamic oscillatory shear rheological properties of ketchup-processed cheese mixtures: Effect of temperature and concentration. J. Food Eng. 103:197-210.

Yöney, Z. 1973. Süt ve Mamulleri Muayene ve Analiz Metotları. Ankara Üniversitesi Basımevi, Ankara, Turkey. 